\title{
A network-based analysis of colon cancer splicing changes reveals a tumorigenesis-favoring regulatory pathway emanating from ELK1
}

\author{
Dror Hollander, ${ }^{1}$ Maya Donyo, ${ }^{1,7}$ Nir Atias, ${ }^{2,7}$ Keren Mekahel, ${ }^{1}$ Zeev Melamed, ${ }^{1,8}$ \\ Sivan Yannai, ${ }^{1}$ Galit Lev-Maor, ${ }^{1}$ Asaf Shilo, ${ }^{3}$ Schraga Schwartz, ${ }^{4}$ Iris Barshack, ${ }^{5,6}$ \\ Roded Sharan, ${ }^{2}$ and Gil Ast ${ }^{1}$
}

${ }^{1}$ Department of Human Molecular Genetics and Biochemistry, Sackler Faculty of Medicine, Tel Aviv University, Ramat Aviv 69978, Israel; ${ }^{2}$ Blavatnik School of Computer Science, Tel Aviv University, Ramat Aviv 69978, Israel; ${ }^{3}$ Department of Biochemistry and Molecular Biology, Institute for Medical Research Israel-Canada, The Hebrew University-Hadassah Medical School, Jerusalem 91120 , Israel; ${ }^{4}$ Department of Molecular Genetics, Weizmann Institute, Rehovot 76100, Israel; ${ }^{5}$ Department of Pathology, Sheba Medical Center, Ramat Gan 52621, Israel; ${ }^{6}$ Sackler Faculty of Medicine, Tel Aviv University, Ramat Aviv 69978, Israel

\begin{abstract}
Splicing aberrations are prominent drivers of cancer, yet the regulatory pathways controlling them are mostly unknown. Here we develop a method that integrates physical interaction, gene expression, and alternative splicing data to construct the largest map of transcriptomic and proteomic interactions leading to cancerous splicing aberrations defined to date, and identify driver pathways therein. We apply our method to colon adenocarcinoma and non-small-cell lung carcinoma. By focusing on colon cancer, we reveal a novel tumor-favoring regulatory pathway involving the induction of the transcription factor MYC by the transcription factor ELK1, as well as the subsequent induction of the alternative splicing factor PTBP1 by both. We show that PTBPI promotes specific RACl, NUMB, and PKM splicing isoforms that are major triggers of colon tumorigenesis. By testing the pathway's activity in patient tumor samples, we find ELKI, MYC, and PTBP1 to be overexpressed in conjunction with oncogenic KRAS mutations, and show that these mutations increase ELKI levels via the RAS-MAPK pathway. We thus illuminate, for the first time, a full regulatory pathway connecting prevalent cancerous mutations to functional tumorinducing splicing aberrations. Our results demonstrate our method is applicable to different cancers to reveal regulatory pathways promoting splicing aberrations.
\end{abstract}

[Supplemental material is available for this article.]

Alternative splicing is an evolutionarily conserved mechanism that increases transcriptomic and proteomic diversity by allowing the generation of multiple mRNA products from a single gene. It is highly prevalent as $>95 \%$ of human multiexonic genes undergo alternative splicing (Pan et al. 2008; Wang et al. 2008b). Numerous exonic and intronic cis-acting sequences can either enhance or repress splicing unit recognition pending on binding of trans-acting alternative splicing factors (Guigo and Valcarcel 2006). One of these factors is the polypyrimidine tract-binding protein PTBP1 (previously known as PTB). PTBP1 is a heterogeneous nuclear ribonucleoprotein that binds RNA via four domains of varying functionality (Mickleburgh et al. 2014) and can act as a repressive or as an enhancing alternative splicing regulator (Xue et al. 2009; Keppetipola et al. 2012).

Three main types of evidence have established a strong connection between alternative splicing and cancer development. First, several alternative splicing factors, such as SRSF1, RBFOX2, PTBP1, HNRNPA1, HNRNPA2B1, and SRSF6, are overexpressed in different cancer tissues and display oncogenic properties (Karni et al. 2007; Cooper et al. 2009; Venables et al. 2009; David and Manley 2010; Golan-Gerstl et al. 2011; Cohen-Eliav et al. 2013). Second, changes in the splicing patterns of various alternative splicing events were identified in tumors in comparison with their corresponding normal tissues (Kim et al. 2008; Liu et al. 2012; Pesson et al. 2014), and some were demonstrated to play prominent roles in carcinogenesis (Srebrow and Kornblihtt 2006; Wang and Cooper 2007; Papasaikas et al. 2015). Third, splicing factors, such as SF3B1 and U2AF1, are highly mutated in several malignancies (Graubert et al. 2011; Quesada et al. 2012). However, the underlying causes of the cancerous up-regulation of alternative splicing factors as well as the specific inducers of splicing aberrations in tumors are still largely unknown.

Colon and rectal tumors constitute a major cause of cancer mortality, as an estimated 1 million individuals worldwide develop them yearly with a disease mortality rate of $\sim 33 \%$ in the developed world (Cunningham et al. 2010). The molecular mechanism in colon tumorigenesis is largely nonhereditary and is mainly triggered by a series of oncogene-activating mutations and tumor suppressor gene-deactivating mutations in a relatively small set of genes (Fearon 2011). The most prevalent are those

\begin{abstract}
${ }^{7}$ These authors contributed equally to this work.
${ }^{8}$ Present address: Ludwig Institute for Cancer Research, University of California at San Diego, La Jolla, CA 92093-0670, USA

Corresponding authors: roded@post.tau.ac.il, gilast@post.tau.ac.il Article published online before print. Article, supplemental material, and publication date are at http://www.genome.org/cgi/doi/10.1101/gr.193169.115.
\end{abstract}

() 2016 Hollander et al. This article is distributed exclusively by Cold Spring Harbor Laboratory Press for the first six months after the full-issue publication date (see http://genome.cshlp.org/site/misc/terms.xhtml). After six months, it is available under a Creative Commons License (Attribution-NonCommercial 4.0 International), as described at http://creativecommons.org/licenses/ by-nc/4.0/. 
found in APC, KRAS, and TP53 (Wood et al. 2007; Fearon 2011). Mutations in these genes lead to up-regulation of the Wnt and RAS-MAPK signaling pathways and to down-regulation of the TP53 pathway, resulting in the overexpression of the oncogenic transcription factor MYC, increased cell proliferation, and, eventually, colon carcinogenesis (Fearon 2011; The Cancer Genome Research Atlas Network 2012b).

Several alternative splicing events have been reported to display different splicing patterns in colon tumors compared with the normal tissue. Three noteworthy splicing pattern differences are the inclusion of $R A C 1$ exon $3 \mathrm{~b}$, the increased inclusion of NUMB exon 9, and the inclusion of PKM exon 10 in conjunction with exon 9 exclusion (Jordan et al. 1999; Hardt et al. 2003; Misquitta-Ali et al. 2010). These specifically contribute to colon tumorigenesis through proteomic changes that cause Notch pathway activation and promotion of aerobic glycolysis, genomic instability, and epithelial-mesenchymal transition (Radisky et al. 2005; Christofk et al. 2008; Misquitta-Ali et al. 2010; Bechara et al. 2013; Myant et al. 2013). In addition, PRPF6, a member of the tri-snRNP (small ribonucleoprotein) spliceosome complex, was shown to positively affect colon cancer proliferation (Adler et al. 2014).

Several pathways involving transcription factor activity affecting alternative splicing factors have been shown to undergo overactivation or disruption in different cancer types, thus contributing to carcinogenesis (David and Manley 2010; Das et al. 2012). Nevertheless, current knowledge concerning alternative splicing regulation in cancer leaves much to be desired, calling for a systematic examination of the pathways leading to cancerous splicing aberrations.

\section{Results}

\section{Constructing a physical interaction network underlying cancerous splicing aberrations}

Deciphering the regulation of alternative splicing in cancer is fundamental to our understanding of the disease processes and ways to combat them. To study the pathways that govern alternative splicing factor activity and, subsequently, splicing changes in cancer, we integrated large-scale protein-DNA, protein-RNA, and protein-protein physical interaction data together with gene expression and alternative splicing data into a single network (Methods). Briefly, we analyzed high-throughput cross-linking and immunoprecipitation (CLIP) data of human alternative splicing factors (Sanford et al. 2009; Xiao et al. 2009; Xue et al. 2009; Yeo et al. 2009; Hafner et al. 2010; Konig et al. 2010; Wang et al. 2010; Kishore et al. 2011; Lebedeva et al. 2011; Mukherjee et al. 2011; Tollervey et al. 2011; Huelga et al. 2012) to determine their protein-pre-mRNA interactions in regions encompassing all internal exons in multiexonic genes and 300-bp-long flanking intronic regions (15,501 interactions in total). In addition, 16,320 human protein-DNA interactions between transcription factors and the genes they bind, as well as 45,055 protein-protein interactions, were derived from chromatin immunoprecipitation (ChIP), yeast two-hybrid, and coimmunoprecipitation screens, as well as from publicly available databases (Yosef et al. 2011; Hegele et al. 2012). All interactions were assigned confidence scores as previously described (Yosef et al. 2011). This combined network is a powerful resource linking three regulatory layers, which are likely to work in coordination in the context of a biological process of interest. It is available through ANAT (Yosef et al. 2011), a free
Cytoscape (Saito et al. 2012) plug-in for network analysis (http:// www.cs.tau.ac.il/ bnet/ANAT). An initial examination of alternative splicing factor protein-protein interaction data in our network revealed a distinct module of interacting factors that includes several cancer-associated proteins (Supplemental Fig. S1; Supplemental Results).

To focus on splicing aberrations in cancer, we analyzed transcriptome-wide data of cancerous and normal tissues spanning 24,426 alternative splicing events and 18,093 genes (Castle et al. 2008), identifying alternative splicing events that exhibit significant splicing differences in tumors compared with corresponding normal tissues (Methods). We then searched the combined network for high-confidence subnetworks connecting transcription factors with the determined differentially spliced events in tumors (schematically depicted in Fig. 1A). The search algorithm builds upon a previously described method by Yosef et al. (2009) and additionally assigns significance values to each inferred subnetwork that reflect the gene expression changes of its members in cancer. Briefly, the algorithm jointly optimizes the size of the inferred subnetwork, the confidence of its member interactions, and the confidence of each of the paths connecting a transcription factor to a differentially spliced event. Significance levels are calculated according to the cancerous gene expression changes in the inferred subnetwork in comparison with the normal tissue gene expression (Methods). The resulting subnetworks coherently describe significant regulatory pathways that emanate from a transcription factor and are likely to induce splicing aberrations.

\section{Network leading to colon cancer splicing changes emanates from ELK1}

We applied our method to construct the splicing interactomes of colon adenocarcinoma and lung squamous cell carcinoma NOS (Fig. 1B; Supplemental Fig. S2, respectively) using transcriptomic data of tumors and normal tissues (Castle et al. 2008). Interestingly, the constructed subnetworks were significantly enriched for cancer-associated Kyoto Encyclopedia of Genes and Genomes (KEGG) pathways (Kanehisa et al. 2012) and genes included in the Catalogue of Somatic Mutations in Cancer (COSMIC; Forbes et al. 2011), two gold standard references for the evaluation of cancerous gene and protein annotations (Supplemental Table S1). Focusing on colon cancer, the only significant subnetwork was that originating in ELK1 (Methods), a member of the oncogenic ETS family of transcription factors. The network reveals a pathway involving ELK1, MYC, and PTBP1, accounting for the majority of alternatively spliced events. Intriguingly, PTBP1 is an alternative splicing factor previously shown to be overexpressed in brain tumors and implicated in their formation (David et al. 2010). It has also been suggested to be involved in breast cancer epithelial-mesenchymal transition (Shapiro et al. 2011; He et al. 2014). In the pathway we identified, ELK1 directly regulates the gene expression of PTBP1 and $M Y C$, an oncogenic transcription factor that plays an important role in colon tumor development (Fearon 2011). Downstream from ELK1, MYC also directly regulates the transcriptional induction of PTBP1 as well as that of $H N R N P F$, an alternative splicing factor shown to be overexpressed in colon cancer (Balasubramani et al. 2006). PTBP1 up-regulation by MYC is known to promote lung tumor formation (Clower et al. 2010; David et al. 2010), but the addition of MYC activation by ELK1 and the MYC-independent activation of PTBP1 by ELK1 have not been previously reported in the context of cancer formation.

\section{Genome Research}

www.genome.org 

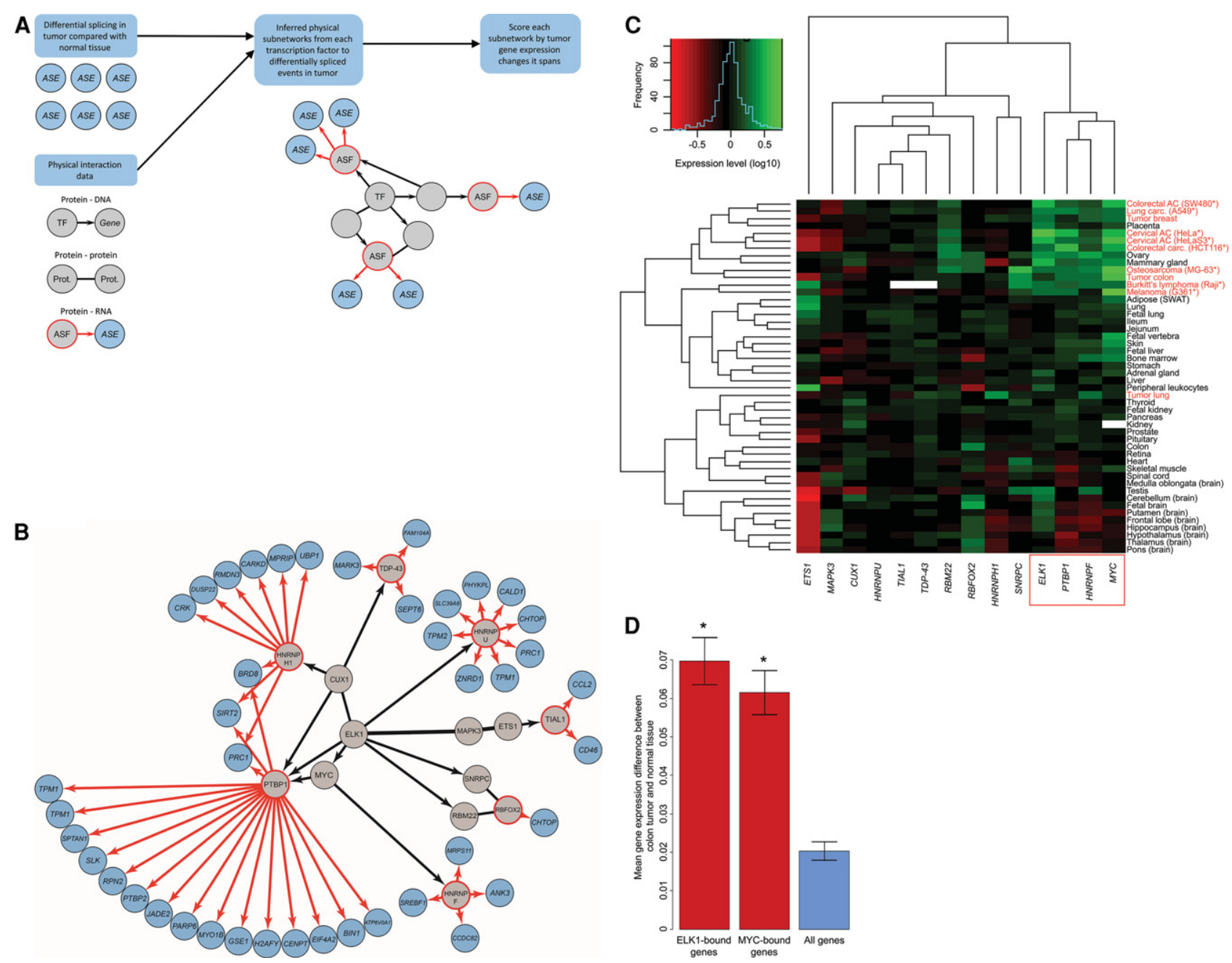

Figure 1. Physical interaction network leading to colon cancer splicing changes. (A) A diagram illustrating the construction of the cancerous splicing interactome connecting transcription factors (TFs) to alternative splicing events (ASEs) exhibiting splicing pattern differences in tumors compared with normal tissues (alternative splicing factor [ASF]). (B) ELK1 colon tumor subnetwork. Gene names of exons exhibiting significant splicing changes in the colon tumor compared with the normal tissue are colored light blue; all other genes and proteins are colored gray. Alternative splicing factors are marked by red borders. Protein-DNA and protein-pre-mRNA interactions are marked by black and red directed arrows, respectively. (C) Hierarchical clustering of ELK1 subnetwork member gene expression in 48 human tissue and cell lines. Tumor and cancer cell line names are colored red. Cell lines are marked by an asterisk. White boxes denote missing reads. The color key legend includes a histogram of the gene expression level distribution. $(D)$ Mean gene expression level difference between colon tumor and normal tissue of genes with promoters bound by ELK1 $(n=1937)$, genes with promoters bound by MYC $(n=3226)$, and all genes $(n=18,093)$; arbitrary units. Error bars, SEM.

\section{Colon cancer up-regulation of ELK1, MYC, and their target genes}

To support the identified regulatory pathway in the ELK1 subnetwork, we analyzed the subnetwork's gene expression profile using transcriptome-wide data spanning 48 human tissues and cell lines, including the colon tumor, cell lines derived from it, and the corresponding normal colon (Fig. 1C; Castle et al. 2008). Our results demonstrate that a gene cluster including ELK1, MYC, PTBP1, and $H N R N P F$ exhibits similar gene expression levels. This cluster substantially differs in its expression pattern from other network members and, most importantly, is up-regulated in several tumors and cancer cell lines, including the colon tumor. To test whether ELK1 and MYC are overactive in colon cancer compared with the normal colon, we examined the gene expression changes of their targets. ELK1 and MYC ChIP coupled with high-throughput sequencing (ChIP-seq) data (obtained from the ENCODE Project Consortium 2012) were analyzed to identify high-confidence read peaks of gene promoters bound by the proteins (Methods). We then measured the mean difference in the expression level of these genes between tumor and normal colon tissues (Fig. 1D). ELK1-bound and MYC-bound genes exhibited significantly higher mean differences in expression levels compared with all genes (two-sided Student's $t$-test; $P=9.67 \times 10^{-14}$ and $P=2.35 \times 10^{-11}$, respectively), implying that ELK1 and MYC are indeed overactive in colon cancer. Overall, these results reinforce the identified regulatory pathway involving ELK1 and MYC, which could be implicated in colon cancer formation.

PTBP1, RBFOX2, HNRNPH1, and HNRNPF expression levels are positively correlated with cancer-associated splicing isoforms their proteins bind

In a previous work, we demonstrated a correlative relationship between the gene expression of an alternative splicing factor and the 
splicing events it regulates (Llorian et al. 2010). To examine such relations in the context of the ELK1 subnetwork, we tested whether the gene expression levels of alternative splicing factors identified in the subnetwork were correlated with the splicing changes of exons their proteins bind. All high-throughput CLIP-derived peaks located in the vicinity of differentially spliced exons in the colon tumor compared with the normal colon were used in the analysis. We found that four of the seven alternative splicing factors in the ELK1 subnetwork-PTBP1, RBFOX2, HNRNPH1, and $H N R N P F$ - exhibit strong positive correlations (Fig. 2A). Of these, $P T B P 1$, the alternative splicing factor that interacts with the highest number of differentially spliced events in the subnetwork, also displays the strongest correlations with the alternative exons bound by it (mean $R=0.51$ ). This indicates that PTBP1 may promote production of these cancerous splicing isoforms. The strong correlations exhibited by RBFOX2 (mean $R=0.5$ ) are in accordance with evidence suggesting that this factor drives mesenchymal tissue-specific splicing in both tumors and normal tissues (Venables et al. 2013). Furthermore, analyses of tissue-specific patterns of alternative splicing and the gene expression levels of alternative splicing factors revealed similar tissue clusters, including one consisting of several tumors and cancer cell lines (Supplemental Fig. S3; Supplemental Results), further suggesting that alternative splicing factor transcriptional changes in cancer may play a role in bringing forth cancerous alternative splicing programs.

\section{In silico identification of colon cancer alternative splicing regulators}

Based on our findings, we hypothesized that the relationship between splicing changes and alternative splicing factor gene expression could be used to identify additional factors that regulate splicing aberrations in colon cancer, for which high-throughput CLIP data are currently unavailable. Moreover, not all possible RNA targets are identified within a single high-throughput CLIP experiment as the purified RNA molecules in it only correspond to RNAs bound at the moment of cross-linking (Kloetgen et al. 2014). Our analysis could therefore determine additional regulatory targets (see Supplemental Discussion). To this end, we compiled a list of 54 experimentally validated alternative splicing events shown to undergo a splicing pattern change in colon tumor samples compared with corresponding normal tissue samples (Jordan et al. 1999; Hardt et al. 2003; Ghigna et al. 2005; Gardina et al. 2006; Klinck et al. 2008; Thorsen et al. 2008; Venables et al. 2009; Langer et al. 2010; Misquitta-Ali et al. 2010; Pio et al. 2010; Choi et al. 2011; Ishimoto et al. 2011; Liu et al. 2012; Miura et al. 2012; Seo et al. 2012). We then identified the potential regulators of these cancerous splicing changes by the number and strength of determined Pearson correlations between the splicing changes of the 54 alternative events across 48 human tissues and cell lines and the gene expression of alternative splicing factors in the same tissues (Methods). The mean coefficient values of the five highest ranking alternative factors are depicted in Figure 2B.

Here, too, PTBP1 exhibited the strongest relations with the highest number of alternative splicing events (mean $R=0.53$ ). It is predicted to induce the cancerous isoform of 13 alternative events, 10 of which lack significant CLIP-seq read peaks (Fig. 2C,D; data not shown). Reassuringly, PTBP1 has been shown to regulate four of the predicted targets in the PKM, TPM1, ACTN1, and ATP2B4 genes in other tissues (Clower et al. 2010; Llorian et al. 2010; Mallinjoud et al. 2014). In accordance with Figure
2A, HNRNPF displayed strong correlations with colon cancer splicing patterns (mean $R=0.44$ ). The $Q K I$ and $C E L F 2$ alternative splicing factors exhibited the strongest negative relations with colon cancer splicing patterns (mean $R=-0.47$ ). Interestingly, the expression of both proteins has been reported to induce a tumor-suppressing effect (Ramalingam et al. 2012; Zong et al. 2014). Our results therefore indicate that PTBP1 could play a previously unknown role in promoting a number of colon cancer alternative splicing changes, while QKI and CELF2 may have an opposite effect.

\section{PTBP1 promotes colon tumorigenesis-triggering splicing isoforms}

To validate PTBP1's regulatory role in inducing cancerous splicing aberrations in the colon based on our analysis (Fig. 2B), RNA interference-mediated (siRNA) knockdown of PTBP1 and of PTBP2 (previously known as $n P T B)$, its functionally redundant paralog (Spellman et al. 2007), was performed in the HCT116 colorectal carcinoma cell line. Splicing pattern changes of PTBP1's predicted targets after siRNA treatment were examined via RT-PCR. Upon treatment with the control siRNA, all examined alternative splicing events displayed the same splicing patterns as those originally identified in the tumor samples (Fig. 2C,D; Supplemental Fig. S4A, B, and data not shown; Jordan et al. 1999; Hardt et al. 2003; Gardina et al. 2006; Thorsen et al. 2008; Misquitta-Ali et al. 2010). Overall, 11 of 13 (85\%) predicted PTBP1 targets exhibited a splicing pattern change following treatment with siRNA directed against PTBP1 and PTBP2 in accordance with PTBP1's predicted effect (Fig. 2C; Supplemental Fig. S4A), shifting splicing patterns to those observed in normal colon samples, and two in the opposite direction (Fig. 2D; Supplemental Fig. S4B). A validation of PTBP1 and PTBP2 protein levels upon siRNA treatment demonstrated they were indeed highly reduced (Fig. 2E).

The tested alternative splicing changes in the RAC1, NUMB, and $P K M$ genes were shown to affect protein levels or functions and play an important part in tumorigenesis (see Discussion) (Radisky et al. 2005; Christofk et al. 2008; Misquitta-Ali et al. 2010; Bechara et al. 2013; Myant et al. 2013). Other events are not specifically known to be involved in cancer development but are located within genes that are: TPM1, DNMT3B, NCOR2 (also known as SMRT), and SLK (Jin et al. 2009; Roovers et al. 2009; Choi et al. 2012; Margalef et al. 2012). As the total number of nucleotides in some of these alternative segments is not a multiple of three, their respective addition or deletion from the mRNA is likely to cause a premature stop codon, which could lead to the formation of a truncated protein or to mRNA degradation via nonsensemediated mRNA decay (NMD). PTBP1 therefore induces splicing pattern changes implicated in cancer development in addition to its interactions with CLIP-derived targets (Fig. 2F). Furthermore, our results demonstrate the utility of our method in identifying proteins that regulate cancerous alternative splicing changes.

\section{ELK1 overexpression activates a regulatory pathway that involves MYC and PTBPI}

By focusing on the discovered regulatory pathway involving ELK1, MYC, and PTBP1, we wished to study its induction in a colon tumor-derived cell line. By use of HCT116 cells, the binding of ELK1 to the MYC and PTBP1 promoter regions (Fig. 3A,B), as well as that of MYC to the PTBP1 promoter region (Fig. 3C), was confirmed via ChIP followed by quantitative real-time-PCR (qPCR; one-sided Student's $t$-test; $P=0.002, P=0.001$, and $P=$

\section{Genome Research}

www.genome.org 
A

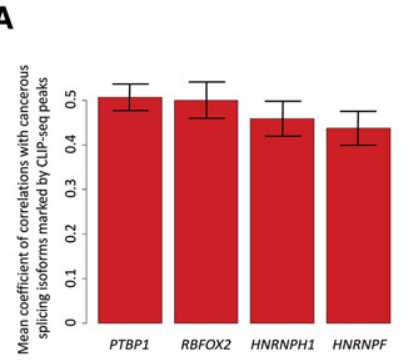

B

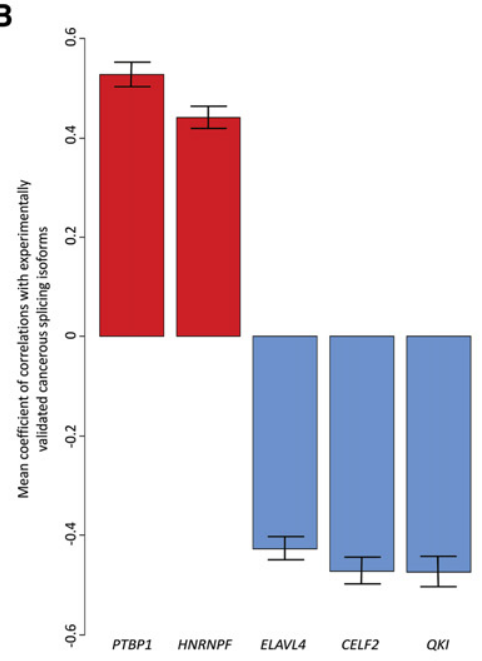

C

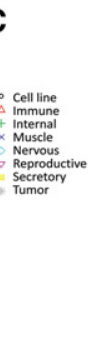

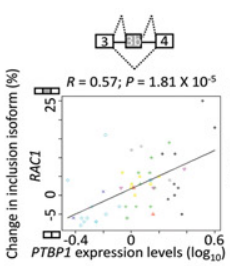
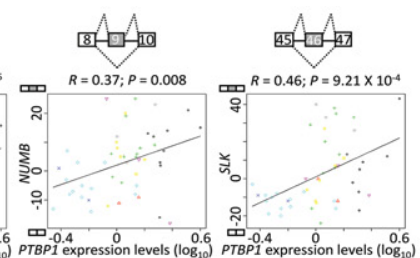

RAC1
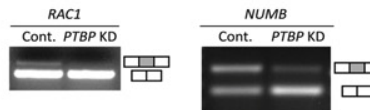

近- -4

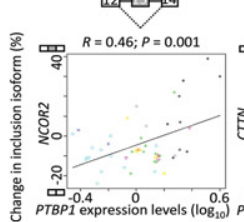

마는 10

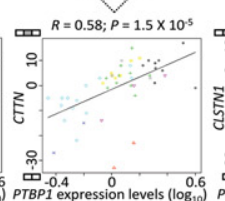

=

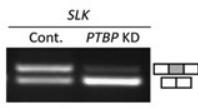

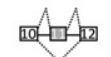
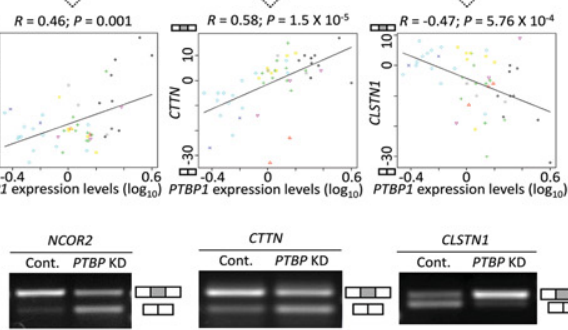

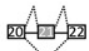

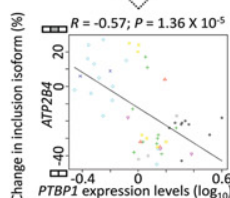

8 (1)
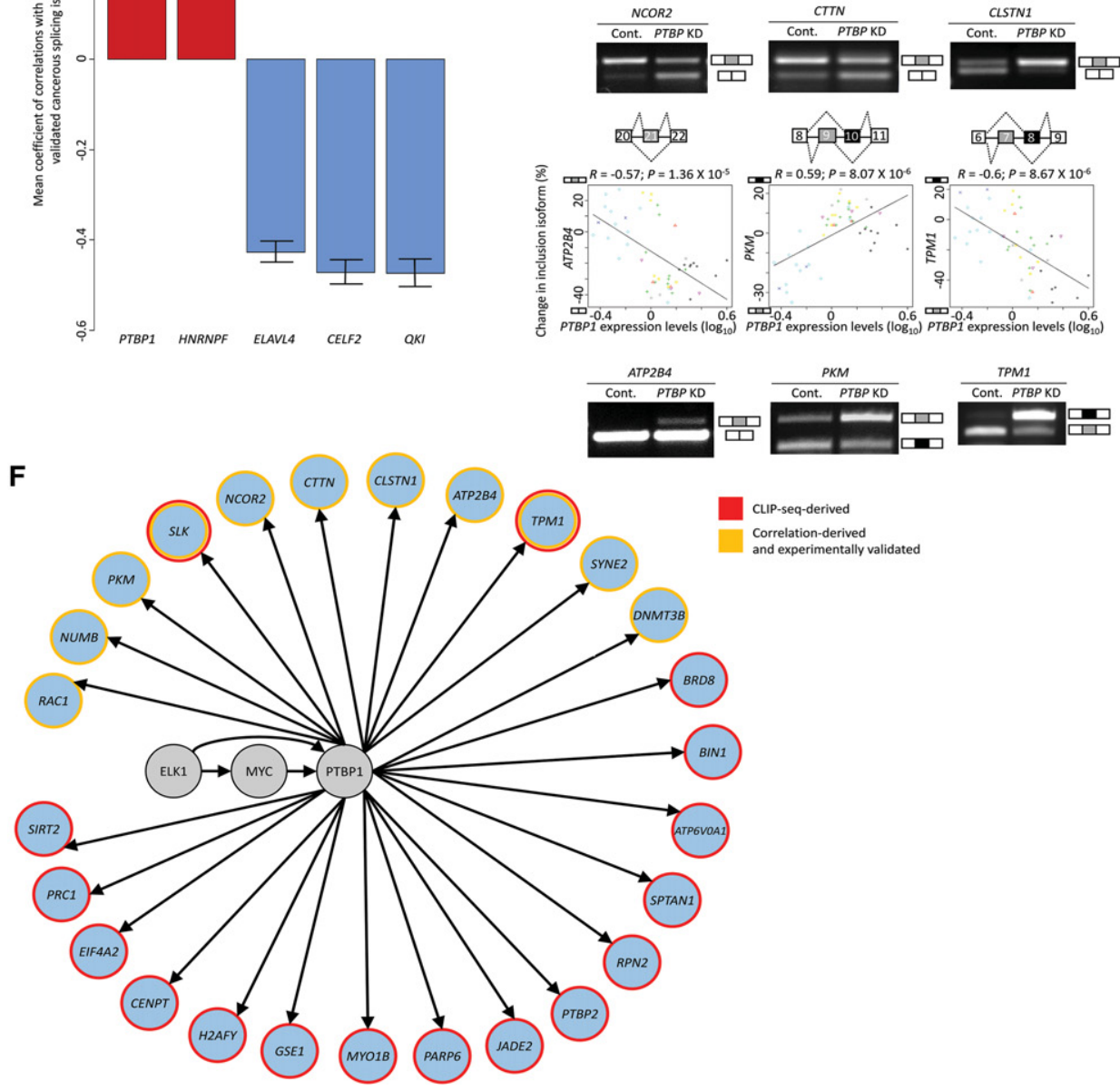

F

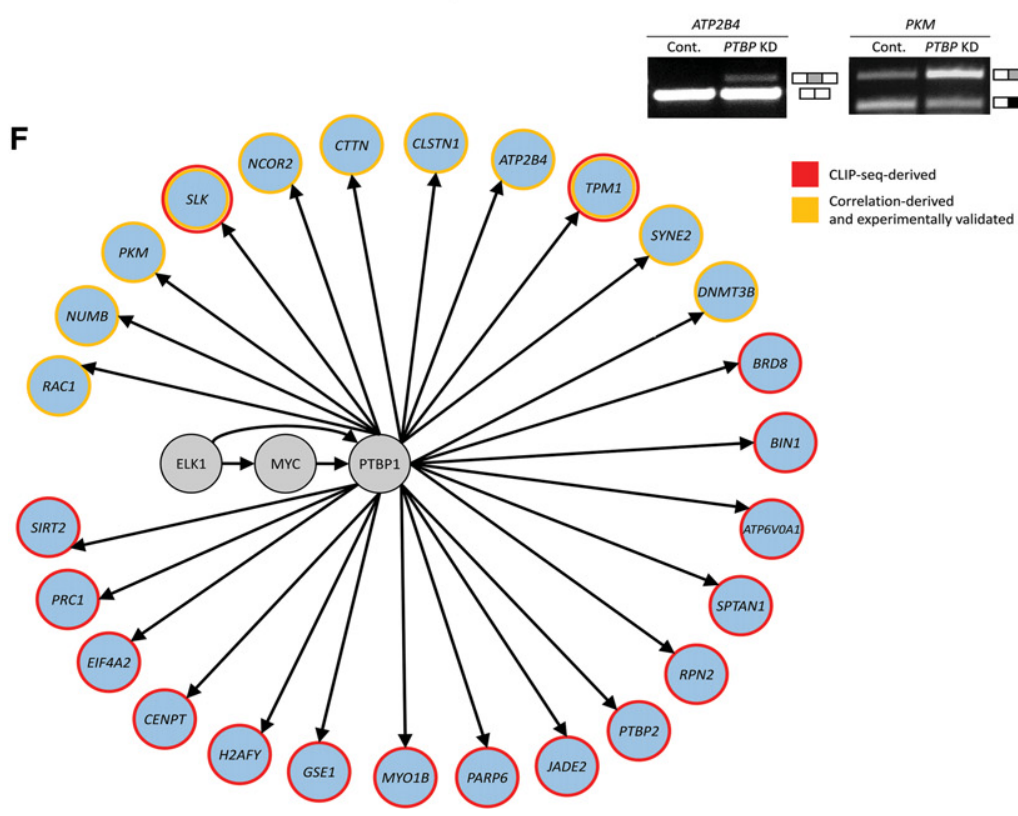

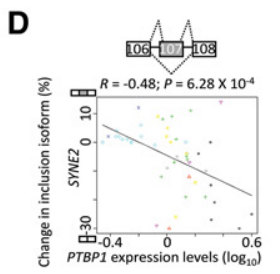
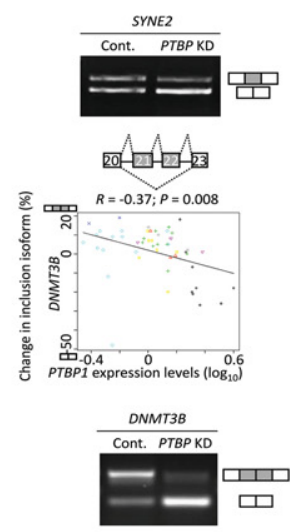

E

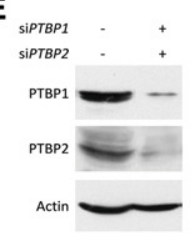

Figure 2. PTBP1 promotes colon tumorigenesis-triggering splicing isoforms. (A) Mean Pearson coefficients of ELK1 subnetwork alternative splicing factor gene expression correlations with splicing changes of all cancerous isoforms bound by these factors. Genes displaying fewer than five statistically significant correlations were omitted. Error bars, SEM. (B) The five highest ranking mean Pearson coefficients of alternative splicing factor gene expression correlations with the splicing changes of experimentally validated cancerous splicing isoforms. Error bars, SEM. (C,D, top) Per each alternative splicing event predicted to be regulated by PTBP1, the Pearson correlation between PTBP1 gene expression and the change in inclusion splice form across 48 human tissues and cell lines is depicted. Tissue and cell line groups are represented by different symbols. Each diagram depicts exon positions and the possible transcripts arising from the alternative splicing event. (Bottom) RT-PCR analysis of the alternative splicing event in HCT116 cells treated with either control siRNA (Cont.) or siRNA directed against PTBP1 and PTBP2 (PTBP KD) is presented as well. PKM and TPM1 RT-PCR products were digested with Pstl. (E) HCT116 cells were transfected with control siRNA or siRNA directed against PTBP1 (siPTBP1) and PTBP2 (siPTBP2), and later cell extracts were subjected to Western blot analysis with the indicated antibodies. (F) Pathway connecting ELK1 with genes including PTBP1-affected and PTBP1-bound exons exhibiting splicing pattern changes in the colon tumor compared with the normal colon (genes colored light blue; other proteins are colored gray). Genes including exons derived from the analysis in $B$ and validated in $C$ and $D$ are marked by yellow borders. Genes including PTBP1-bound exons are marked by red borders. 
A
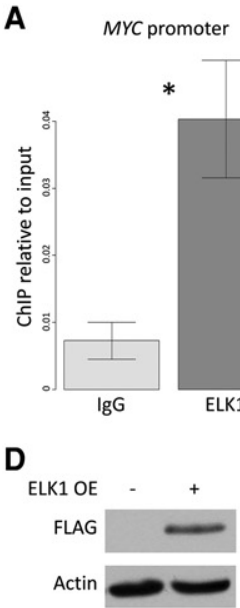

Intergenic region (downstream of $M Y C$ )
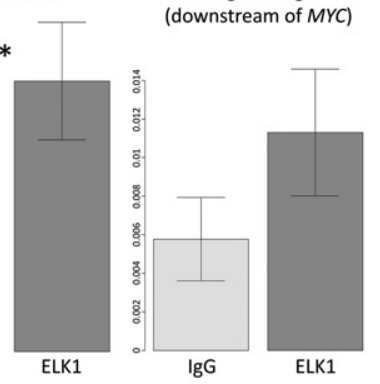

$\mathrm{E}$
B
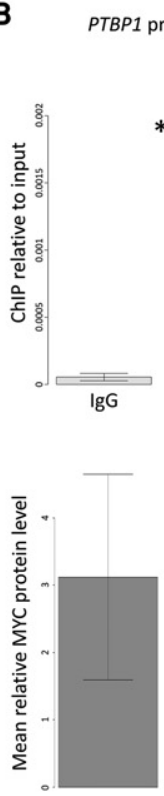
(upstream of PTBP1)
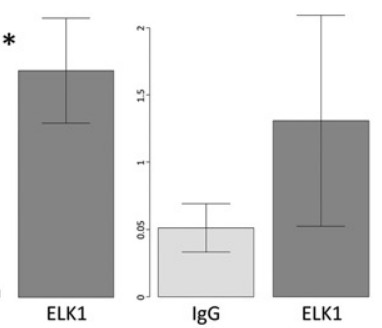

C

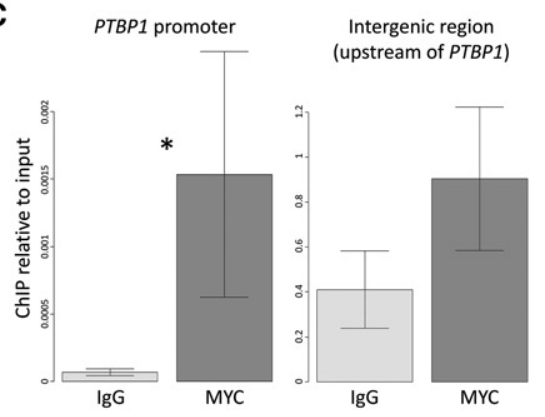

$\mathbf{F}$
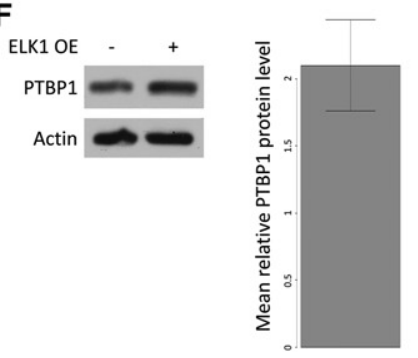

Figure 3. ELK1 activates a regulatory pathway that involves MYC and PTBP1. ( $A-C) \mathrm{HCT} 116$ cells were subjected to ChIP with antibodies against ELK1 $(A, B)$ or MYC (C). Immunoprecipitated DNA was quantified by qPCR with primers specific to the MYC $(A)$ and PTBP1 $(B, C)$ promoter regions as well as intergenic regions used as negative controls (Supplemental Methods). Bars, mean values of four $(A, B)$ or five $(C)$ independent experiments normalized to input (Supplemental Methods). Error bars, SEM. Asterisks indicate $P=0.002, P=0.001$, and $P=0.004$, respectively; one-sided Student's $t$-test. ( $D-F$ ) HCT116 cells were transfected with a plasmid containing CDNA encoding ELK1 (ELK1 OE) or an empty vector in three independent experiments. Cell extracts were subjected to Western blot analysis with the indicated antibodies. Relative protein levels were quantified using ImageJ (Schneider et al. 2012). Error bars, SEM.

0.004, respectively). Additionally, to examine downstream effects on MYC and PTBP1 upon ELK1 level modulation, HCT116 cells were transfected with a plasmid containing cDNA encoding ELK1. Upon ELK1 overexpression (Fig. 3D), endogenous MYC and PTBP1 protein levels were 3.12-fold and 2.1-fold higher on average, respectively, than in cells expressing normal levels of ELK1 (Fig. 3E,F; Supplemental Fig. S4C,D). This demonstrates that ELK1 positively affects the level of these proteins. Several alternative splicing events shown to be affected by PTBP1 knockdown (Fig. 2C) did not display a splicing pattern change in the majority of independent ELK1 overexpression experiments (data not shown). We hypothesize PTBP1 binding to these RNA targets may be saturated before the increase in endogenous PTBP1 levels that results from ELK1 overexpression. Additionally, analysis of PTBP1-regualted alternative splicing events in the normal colon epithelium cell lines CCD $841 \mathrm{CoN}$ and FHC confirmed that the splicing differences observed between colon tumor and normal colon are indeed cancer associated and do not result from an epithelial-specific splicing program in the tumor, which includes a higher concentration of epithelial cells (Supplemental Fig. S5; Supplemental Results). Overall, our findings demonstrate the activation of the ELK1-induced pathway in a colon cancer cell line.

\section{ELK1, MYC, and PTBP1 are overexpressed in colon tumors compared with matched normal colon samples}

In order to inspect the identified pathway in vivo, we examined the expression patterns of its genes in colon adenocarcinoma samples compared with matched normal tissue samples obtained from 19 patients (Supplemental Table S2). ELK1, MYC, and PTBP1 gene expression levels were measured via qRT-PCR. Interestingly, ELK1 and PTBP 1 were overexpressed in 13 of 19 (68\%) patients. In 10 of these 13 patients, MYC was overexpressed as well as in an addition- al three (Methods). One patient displayed extremely high ELK1, $M Y C$, and PTBP1 expression levels and was therefore discarded from further qRT-PCR analyses. In the remaining 12 patients, $E L K 1, M Y C$, and PTBP1 gene expression levels were, respectively, 5.4-fold, 3.36-fold, and 3.53-fold higher in colon tumors than in their matching normal tissues (one-sided Student's $t$-test; $P=$ $0.02, P=0.04$, and $P=0.01$, respectively) (Fig. $4 \mathrm{~A}$ ). Moreover, as controls, AQP8 and ETS1 gene expression levels were measured (Fig. 4B). Colon tumors were previously shown to express lower levels of AQP8 in comparison with the normal colon (Gardina et al. 2006), and 16 patients indeed displayed lower levels by 25 -fold $(P=0.01)$. ETS1 was connected to the ELK1 subnetwork via a protein-protein interaction, while its gene was not overexpressed in colon tumors (Fig. 1B,C). Our analysis showed that ETS1 gene expression does not significantly differ between colon tumor samples and normal tissue samples $(P=0.16)$. The splicing patterns of PTBP1-regulated alternative events in the normal and tumor samples were similar to those observed in previous analyses of patient samples (Thorsen et al. 2008; Langer et al. 2010; Misquitta-Ali et al. 2010), as well as in Figure 2, C and D, and Supplemental Fig. S4, A and B (Supplemental Fig. S6).

To assess the pathway in a broader context of colon cancer patients, we examined colon and rectal tumor data derived from the Cancer Genome Atlas (Methods) (The Cancer Genome Research Atlas Network 2012b). Notably, ELK1, MYC, and PTBP1 expression profiles in 222 tumors were significantly correlated (Fig. 4C), further validating our identified pathway. Interestingly, ELK1 displayed a stronger relation with $P T B P 1\left(R=0.47 ; P=2.36 \times 10^{-13}\right)$ than that between $M Y C$ and PTBP1 $\left(R=0.27 ; P=4.16 \times 10^{-5}\right)$, providing additional evidence that ELK1 could play an important role in PTBP1 transcriptional induction in colon cancer. The relation between $E L K 1$ and $M Y C(R=0.21 ; P=0.002)$ strengthens our previously described results implying that ELK1 serves as an activator of

\section{Genome Research}

www.genome.org 
A
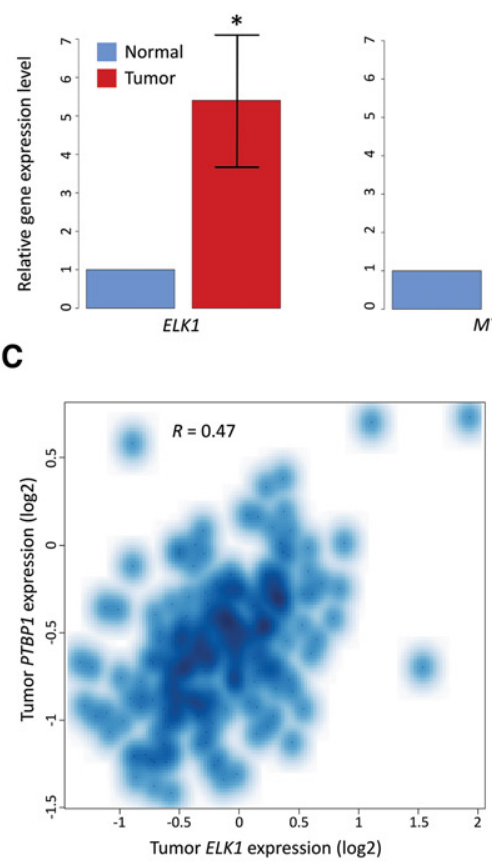

B

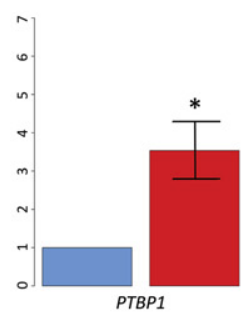

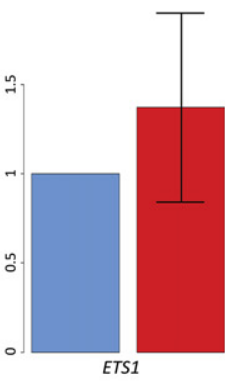

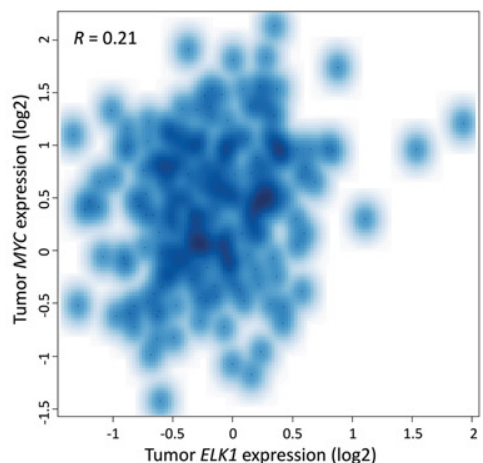

D

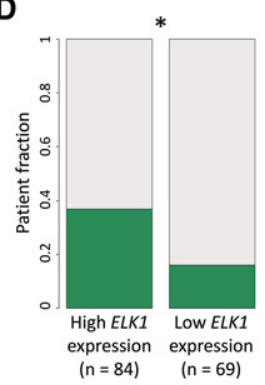

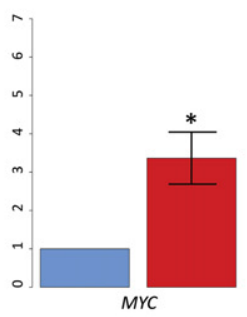

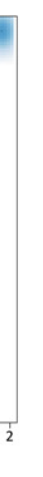

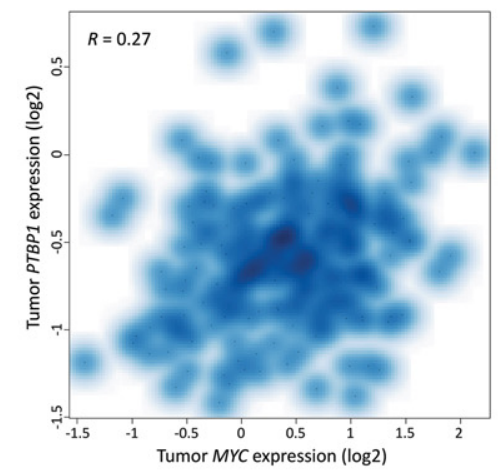
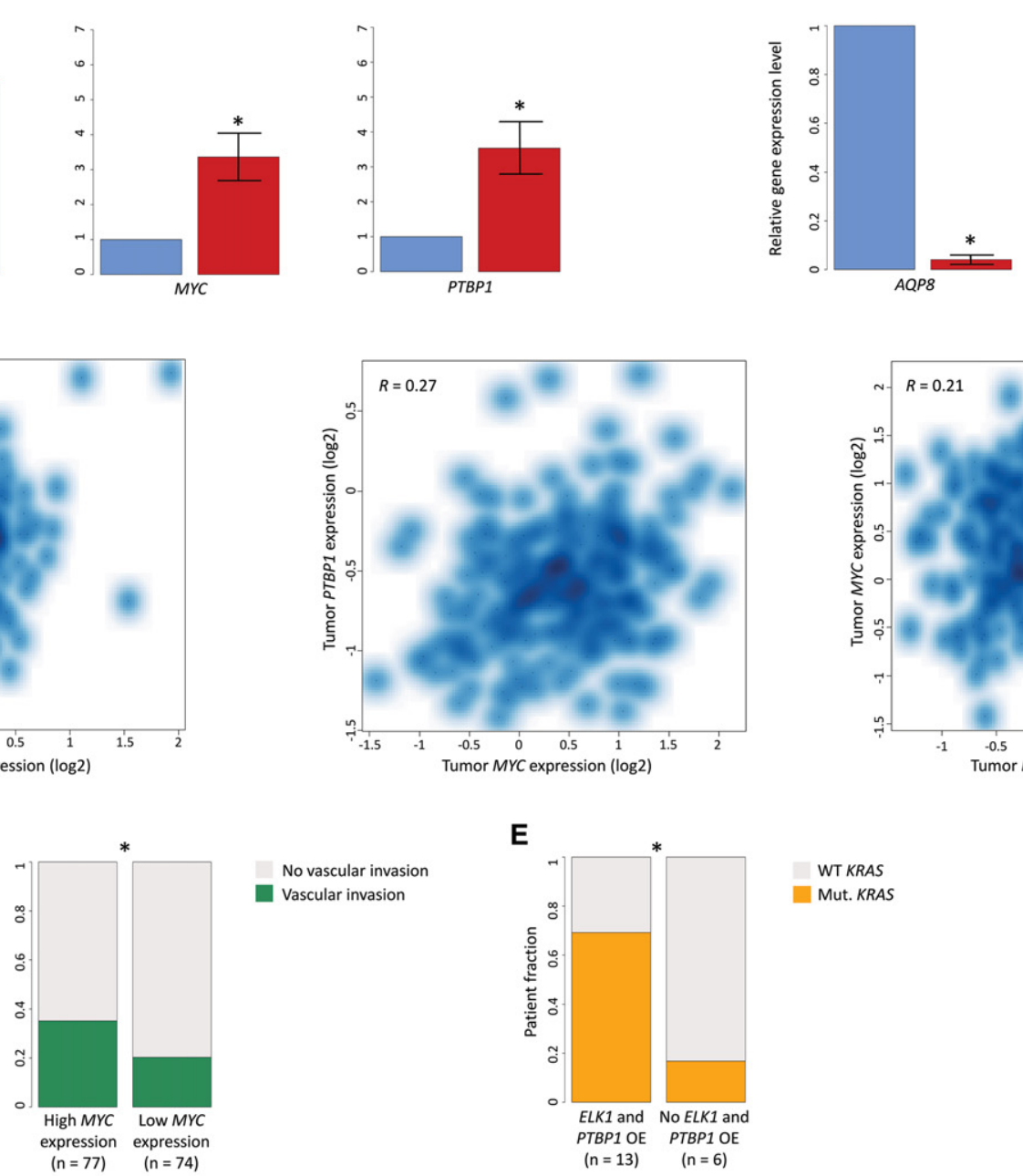

\section{$\mathbf{F}$}

Mut. KRAS Mut. BRAF WT
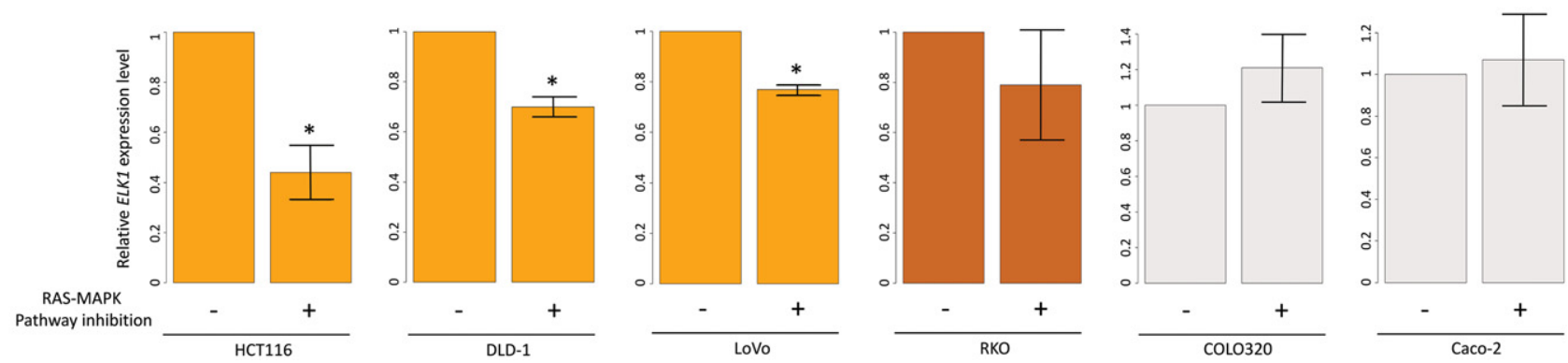

Figure 4. ELK1, MYC, and PTBP1 overexpression in colon tumors compared with matched normal colons results from KRAS activating mutations. $(A, B)$ Total RNA was isolated from colon adenocarcinoma and matched normal colon samples and analyzed by qRT-PCR. ( $A$ ) Mean gene expression levels of ELK1, MYC, and PTBP1 in tumors relative to their matched normal tissues in patients exhibiting tumor overexpression of ELK1 and PTBP1 ( $n=12$ ). Asterisks indicate $P=0.02, P=0.04$, and $P=0.01$, respectively; one-sided Student's $t$-test. (B) As in $A$, but of $A Q P 8$ and $E T S 1$ in patients exhibiting $A Q P 8$ tumor underexpression $(n=15)$. All values were normalized to HPRT1 and GAPDH in the same sample. Error bars, SEM. (C) Smoothed color density representation of the Pearson correlations between the expression levels ( $\left.\log _{2}\right)$ of ELK1 against PTBP1 (left), MYC against PTBP1 (middle), and ELK1 against MYC (right) in 222 colorectal tumor samples. (D) Fraction of patients bearing tumor vascular invasions among those displaying high ELK1 (left) and MYC (right) expression levels and among those exhibiting low ELK1 and MYC expression levels. Asterisks indicate $P=0.003$ and $P=0.03$, respectively; one-sided Fisher's exact test. (E) Fraction of patients bearing KRAS mutations (Mut.) among those overexpressing (OE) ELK1 and PTBP1 in tumors compared with normal tissues (in A) and among those that do not. Asterisk indicates $P=0.05$; one-sided Fisher's exact test. $(F)$ HCT116, DLD-1, LoVo, RKO, COLO320, and Caco-2 cells were treated with $\mathrm{U} 0126$ for $24 \mathrm{~h}$, and total RNA was isolated. Bars, mean ELK1 gene expression levels measured by qRT-PCR in three independent experiments. Values were normalized to GAPDH levels in the same experiments. Error bars, SEM. Asterisks indicate $P=0.03, P=0.01$, and $P=0.01$, respectively; one-sided Student's $t$-test. 
MYC in colon cancer. Examination of Cancer Genome Atlas gene expression data derived from additional cancers (The Cancer Genome Research Atlas Network 2008, 2011, 2012a,c, 2013a) revealed similar correlations in acute myeloid leukemia and clear cell renal cell carcinoma, suggesting the pathway may be active in these cancers as well (Supplemental Fig. S7). We also studied whether a connection exists between our identified pathway and tumor vascular invasion, a predictor of a poor colon cancer prognosis (Lim et al. 2010). Tumors exhibiting high ELK1 and $M Y C$ expression levels developed more vascular invasions compared with tumors expressing low levels of these genes (onesided Fisher's exact test, $P=0.003$ and $P=0.03$, respectively) (Fig. $4 \mathrm{D})$. This finding corroborates our results demonstrating the positive effect these two proteins have on PTBP1 expression and the latter's promotion of splicing isoforms that lead to increased cell proliferation and tumor invasiveness. Overall, our findings indicate that the identified colon cancer-associated pathway is active in vivo, testifying to the utility of our network construction method.

KRAS-hyperactivating mutations lead to ELKI overexpression in tumors through the activity of the RAS-MAPK pathway

We hypothesized that the underlying cause of ELK1 overexpression could be the activation of the RAS-MAPK signaling cascade in colon cancer, as $E L K 1$ is a downstream target of KRAS via this pathway (Lee et al. 2010) and KRAS activating mutations were reported in $40 \%-55 \%$ of colon cancer patients (Wood et al. 2007; Fearon 2011; The Cancer Genome Research Atlas Network 2012b). To eliminate other plausible causes, we scanned the COSMIC database (Forbes et al. 2011) and Cancer Genome Atlas data (The Cancer Genome Research Atlas Network 2012b) for ELK1 mutations or copy number variations in colon and rectal tumors, and indeed, none were observed. Next we scanned the 19 tumor and matched normal tissue samples we had obtained for KRAS mutations (Methods) (Supplemental Table S3). Interestingly, tumors overexpressing ELK1 and PTBP1 compared with matched normal tissues harbored significantly more KRAS activating mutations (Wood et al. 2007; The Cancer Genome Research Atlas Network 2012b) than did tumors that do not exhibit ELK1 and
PTBP1 overexpression (one-sided Fisher's exact test, $P=0.05$ ) (Fig. 4E), suggesting that ELK1 overexpression in colon tumors results from the activity of the mutant KRAS protein.

To test whether it is the mutant KRAS protein that specifically causes ELK1 overexpression through the RAS-MAPK pathway, we inhibited the pathway's activity by treatment with U0126 (Fournier et al. 2011) and subsequently examined ELK1 expression levels via qRT-PCR in several colon cancer cell lines: HCT116, DLD-1, and LoVo, which harbor a hyperactivating KRAS mutation; $\mathrm{RKO}$, which harbors a hyperactivating $B R A F$ mutation that also leads to increased activity of the RAS-MAPK pathway; and COLO320 and Caco-2, which lack mutations leading to increased activity of the RAS-MAPK pathway (Ahmed et al. 2013). A statistically significant decrease in ELK1 expression levels was observed in all three of the cell lines with mutant KRAS (one-sided Student's $t$-test, $P=0.03, P=0.01$, and $P=0.01$, respectively) (Fig. $4 \mathrm{~F}$ ) and in none of the cell lines with wild-type KRAS. This demonstrates that ELK1 transcription is induced by the mutant KRAS through the RAS-MAPK pathway. Thus, our findings illuminate, for the first time, a full regulatory pathway originating from prevalent cancerous mutations in the colon and leading to functional splicing aberrations that induce tumor formation.

\section{Discussion}

Our construction of the colon cancer splicing interactome uncovered a previously unidentified carcinogenesis-favoring regulatory pathway originating in the transcription factor ELK1 (schematically depicted in Fig. 5). This is plausibly due to increased activity of the RAS-MAPK pathway, resulting from oncogenic KRAS mutations found in $40 \%-55 \%$ of colon cancer patients (Wood et al. 2007; Fearon 2011; The Cancer Genome Research Atlas Network 2012b). ELK1 has not been previously implicated in colon tumorigenesis but was identified in breast and lung cancer-associated regulatory pathways (Wood et al. 2007; Goodarzi et al. 2009; Lee et al. 2010). The MYC-independent PTBP1 transcriptional induction could specifically be of therapeutic importance as it presumably contributes to cancer formation without direct MYC involvement, while some potential colon cancer therapy strategies

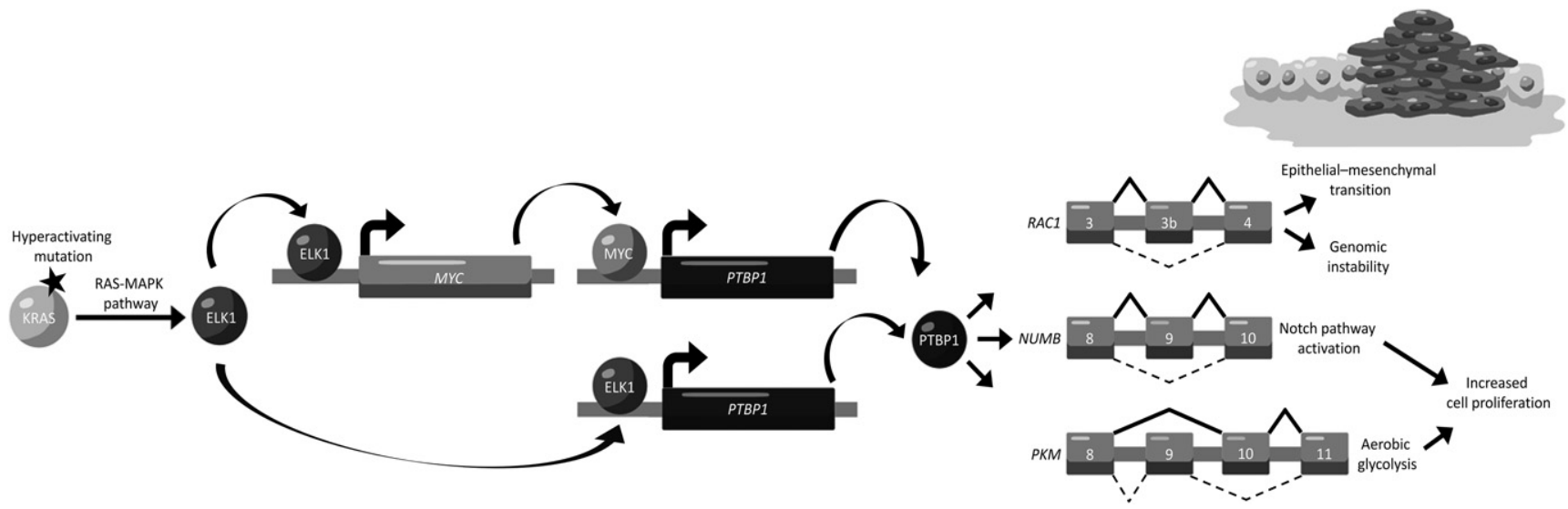

Figure 5. Regulatory pathway leading to colon cancer-promoting splicing aberrations. ELK1 overexpression results from increased activity of the RASMAPK pathway due to hyperactivating KRAS mutations. This leads to increased transcription of MYC and PTBP1. Increased MYC levels also lead to increased PTBP1 levels. PTBP1 overexpression is one of the elements responsible for an alternative splicing profile associated with colon cancer. Among some of the alternative splicing pattern shifts induced by PTBP1 are the inclusion of RAC1 exon 3b, the increased inclusion of NUMB exon 9, and the favoring of PKM exon 10 inclusion over exon 9 inclusion. These contribute to colon adenocarcinoma development by increasing cell proliferation and leading to genomic instability and epithelial-mesenchymal transition.

\section{Genome Research}

www.genome.org 
have focused on inhibiting MYC overactivation (Doudican et al. 2014; Zhang et al. 2014).

Colon adenocarcinoma MYC expression is mainly up-regulated via the beta-catenin-dependent Wnt signaling pathway due to APC mutations in $\sim 70 \%-80 \%$ of patients (Fearon 2011). Our results indicate toward the transcriptional induction of $M Y C$ by ELK1 in an APC-independent fashion. This is in accordance with evidence of $M Y C$ up-regulation via the RAS-MAPK pathway in other cancer types (Dang 2012). Further supporting our results, the cancerous RAC1 isoform, which we found to be promoted by PTBP1, was shown to drive tumor initiation together with the oncogenic mutant KRAS (Zhou et al. 2013). Subsequently, other MYC target genes besides PTBP1 that are known to undergo transcriptional changes in cancer could also be affected by ELK1 elevation. For example, the expression of HNRNPA1 and HNRNPA2B1, alternative splicing factors that are positively regulated by MYC (Clower et al. 2010; David et al. 2010), could also be influenced by ELK1 up-regulation in colon tumors.

The cancerous splicing changes, which we have revealed to be induced by the regulatory pathway emanating from ELK1, have been shown to significantly contribute to colon cancer development (Fig. 5). For example, the protein resulting from the cancerous inclusion of RAC1 exon $3 \mathrm{~b}$ is constitutively active and promotes tumor transformation (Singh et al. 2004). It was shown to increase reactive oxygen species (ROSs), which stimulate epithelial-mesenchymal transition, and cause oxidative damage to DNA and genomic instability (Radisky et al. 2005). Active RAC1 was also identified as a critical protein required for intestinal hyperproliferation (Myant et al. 2013). Additionally, increased inclusion of $N U M B$ exon 9 leads to a reduction in NUMB protein levels (Misquitta-Ali et al. 2010). Since NUMB suppresses the Notch signaling pathway (Westhoff et al. 2009), its reduction increases Notch pathway activity and promotes cell proliferation and tumor formation (Misquitta-Ali et al. 2010; Bechara et al. 2013). Finally, PKM2, the oncogenic PKM isoform that includes exon 10 while lacking exon 9, encodes a protein that shifts cellular metabolism to aerobic glycolysis in the presence of oxygen (the Warburg effect) and promotes tumorigenesis (Christofk et al. 2008). PKM2 also displays other essential nonmetabolic functions in cancer formation such as the regulation of beta-catenin transactivation (Yang et al. 2011), chromosome segregation, and mitosis progression (Jiang et al. 2014).

PTBP1 and PTBP2 negatively regulate each other's levels by affecting the splicing pattern of their pre-mRNAs, and their genes are mainly expressed in different tissues (Boutz et al. 2007; Spellman et al. 2007). While PTBP1 expression is generally low in the nervous system and its transcriptional down-regulation plays an important part in neuronal differentiation (Xue et al. 2013), PTBP2 is mainly expressed in the nervous system (Boutz et al. 2007; Li et al. 2014). In agreement with our results in Figure 2 demonstrating the effect PTBP1 has in promoting colon tumorigenesistriggering splicing isoforms, PTBP1 knockdown significantly reduces the invasive capacity of a colon cancer cell line, T84, and a prostate cancer cell line, PC-3M (Wang et al. 2008a). In this study, PTBP1 knockdown in HeLa cells resulted in the opposite effect. Since PTBP2 expression level elevates in HeLa cells upon PTBP1 knockdown (Spellman et al. 2007; Llorian et al. 2010), we speculate the observed phenomenon in these cells may be due to PTBP2 compensation upon PTBP1 reduction.

Examination of data obtained from the Cancer Genome Atlas for $E L K 1, M Y C$, and PTBP1 expression in cancer samples suggests the identified interactions between them could be active in acute myeloid leukemia and clear cell renal cell carcinoma as well (Supplemental Fig. S7). Our results also suggest ELK1 may strongly affect PTBP1 induction in breast cancer, and are in agreement with previous evidence of positive regulation of PTBP1 by MYC in glioblastoma and lung cancer (Chen et al. 2010; Clower et al. 2010; David et al. 2010). Additionally, the enrichment of our discovered lung cancer subnetworks for KEGG cancerous pathways and COSMIC genes testifies to the general applicability of our network construction method (Supplemental Fig. S2; Supplemental Table S1). It could therefore be applied to transcriptomic data derived from other cancers. It will be of future interest to determine the splicing interactomes of different tumor types and compare between them in order to identify shared pathways and those that are specific to certain cancers. As additional large-scale physical interaction data become publicly available, incorporating these data into our network to provide a more comprehensive overview of significant subnetworks of interest is of importance for future work. Finally, the construction of the cancerous splicing interactome for individual patients based on tissue sample high-throughput RNA sequencing (RNA-seq) data would allow patient comparison and could lead to new insights pertaining to tumor classification and patient prognosis as well as the identification of potential therapeutic targets.

\section{Methods}

\section{Network-based inference of cancerous alternative splicing regulation}

We integrated heterogeneous data into a single network of physical interactions. Specifically, 16,320 protein-DNA interactions connecting 32 transcription factors with the genes they bind and data pertaining to 45,055 protein-protein interactions were derived from publicly available data (Yosef et al. 2011; Hegele et al. 2012). To connect alternative splicing factors with the alternative splicing events they bind, we first annotated all nonoverlapping internal human exons included in multiexonic genes. Annotations were derived from hg18 RefSeq genes, downloaded from the UCSC Genome Browser (Rhead et al. 2010). Then, high-throughput CLIP tag peaks (HITS-CLIP/CLIP-seq, PAR-CLIP, and iCLIP) (Sanford et al. 2009; Xiao et al. 2009; Xue et al. 2009; Yeo et al. 2009; Hafner et al. 2010; Konig et al. 2010; Wang et al. 2010; Kishore et al. 2011; Lebedeva et al. 2011; Mukherjee et al. 2011; Tollervey et al. 2011; Huelga et al. 2012) were detected as previously specified (Hafner et al. 2010; Kishore et al. 2011; Huelga et al. 2012). Finally, the top 5\% scoring peaks overlapping with a window located $300 \mathrm{bp}$ upstream of the annotated exons to 300 bp downstream from them, accounting for 15,501 protein-RNA interactions and 23,527 alternative splicing events, were integrated into the network. The combined network is available at http:// www.cs.tau.ac.il/ bnet/ANAT.

Previously, we described an approach to infer a subnetwork connecting a set of causal proteins with a set of affected proteins (Yosef et al. 2009, 2011). Here, we build upon this approach to connect transcription factors with differentially spliced exons in tumors. Specifically, we retrieved transcriptome-wide microarray data in 48 human tissues, tumors, and cancer cell lines from Castle et al. (2008) and analyzed them to determine the alternative splicing and gene expression tissue profiles of 24,426 alternative splicing events and 18,093 genes (as specified there). Exon annotations in our physical interaction network were merged with those of the alternative splicing events covered by the data of Castle et al. (2008). Alternative splicing events were considered differentially spliced in tumors compared with the normal tissue if they 
displayed a significant splicing change in the tumor compared with a mixed tissue pool while not in the normal tissue compared with a mixed tissue pool, or if both tissue types did and their splicing isoform change difference was $\geq 20 \%$. Each subnetwork, connecting a transcription factor to the events that are alternatively spliced in tumors, was then scored according to the gene expression changes it spans (sum of subnetwork absolute gene expression level differences between the tumor and the normal tissue, excluding subnetwork genes included in it only due to proteinRNA interactions), normalized by its size (number of nodes). These scores were compared with the scores of 100 subnetworks connecting the same transcription factor with random alternative splicing events (random alternative splicing event sets were of the same size as the test set). We only considered significant results with empirical $P$-values lower than 0.1 (for the ELK1 subnetwork, $P=0.09$ ). Finally, we computed the FDR-corrected $P$-values of hypergeometric intersections between the significant subnetworks and either the union of cancer-associated KEGG pathways (Kanehisa et al. 2012) or mutated genes in cancer derived from COSMIC (Supplemental Table S1; Forbes et al. 2011). ANAT source code is available at https://bitbucket.org/rinatias/anat/branch/ OpenSource, and subnetwork analysis and scoring scripts are included as supplemental files.

\section{ChIP-seq analysis}

ELK1, MYC, and input ChIP-seq data were downloaded from the GEO (GSM935326, GSM935320, GSM935339, and GSM817342). Data were aligned to the hg18 human genome assembly using Bowtie (Langmead et al. 2009) while allowing for one mismatch per read, and only uniquely mapped reads were used for further processing. In order to allow compatibility between the various data sets used in our study, NGS reads were not mapped to the most recent human genome assembly (GCRh38). However, it should be noted that only very minor differences, if any, exist between the sequences of the coding regions of the genome in different genome assemblies. Since all the analyses we performed focused solely on genes and mainly at an exon-centric resolution, it is very unlikely that remapping the data to a more recent assembly of the human genome would have any effect on our results, as the vast majority of reads, if not all of them, would align to exactly the same areas in the genome. ChIP-seq peak calling and annotation analyses were carried out using HOMER (Heinz et al. 2010) against input ChIP-seq data as controls. HOMER default definition of promoters as regions spanning $-1 \mathrm{~kb}$ to $+100 \mathrm{bp}$ of transcription start sites was used.

\section{In silico identification of colon cancer alternative splicing regulators}

The Pearson correlations between the splicing profiles of 54 cancer-associated alternative splicing events (Jordan et al. 1999; Hardt et al. 2003; Ghigna et al. 2005; Gardina et al. 2006; Klinck et al. 2008; Thorsen et al. 2008; Venables et al. 2009; Langer et al. 2010; Misquitta-Ali et al. 2010; Pio et al. 2010; Choi et al. 2011; Ishimoto et al. 2011; Liu et al. 2012; Miura et al. 2012; Seo et al. 2012) across all tissues and the gene expression profiles of alternative splicing factors (gene list derived from Chen and Manley 2009 and Hegele et al. 2012) in the same tissues were computed (alternative splicing and gene expression data were derived from Castle et al. 2008). Alternative splicing factor genes not displaying a significant expression level change in colon tumors compared with a mixed tissue pool were discarded as were splicing events with significant isoform changes compared with a mixed tissue pool in only four tissues or less, and statistically insignificant cor- relations $(P>0.05)$. Genes were ranked according to the number of their statistically significant correlations and the mean absolute correlation coefficient values.

\section{TCGA data analysis}

Human colon and rectal cancer gene expression data and tumor characteristics (The Cancer Genome Research Atlas Network $2012 b$ ) as well as acute myeloid leukemia (The Cancer Genome Research Atlas Network 2013b), clear cell renal cell carcinoma (The Cancer Genome Research Atlas Network 2013a), breast cancer (The Cancer Genome Research Atlas Network 2012c), squamous cell lung cancer (The Cancer Genome Research Atlas Network 2012a), glioblastoma (The Cancer Genome Research Atlas Network 2008), and ovarian cancer (The Cancer Genome Research Atlas Network 2011) gene expression data were downloaded from the Cancer Genome Atlas portal (http:// cancergenome.nih.gov/). Colorectal tumors were divided to three equally sized bins according to ELK1 or MYC expression. Per each gene expression profile, tumors included in the top bin were defined as displaying high expression, while those included in the bottom bin were defined as exhibiting low expression.

\section{Cell culture, cloning, and transfection}

HCT116, DLD-1, LoVo, COLO320, and Caco-2 cells were cultured in RPMI1640. RKO cells were cultured in DMEM. Media were supplemented with $0.29 \mathrm{mg} / \mathrm{mL}$ L-glutamine, $100 \mathrm{U} / \mathrm{mL}$ penicillin, and $0.1 \mathrm{mg} / \mathrm{mL}$ streptomycin (Biological Industries) and 10\% fetal calf serum (Sigma) in $37^{\circ} \mathrm{C}$ humidified atmosphere with $5 \% \mathrm{CO}_{2}$. Upon testing, cells were found to be free of mycoplasma contamination. Human PTBP1 and ELK1 coding sequences were amplified by KAPA HiFi HotStart (Kapa Biosystems) and cloned into pX3FLAG-CMV-10 expression vector. HCT116 cells were plated in six-well plates for $24 \mathrm{~h}$ prior to transfection of $500 \mathrm{ng}$ of each vector using TransIT-LT1 reagent (Mirus) and were harvested after $48 \mathrm{~h}$. SiRNA transfection of HCT116 cells was carried out using Lipofectamine RNAiMAX (Invitrogen) according to the manufacturer's protocol with 100 pmol of each of the siPTBP1 and siPTBP2 and with 200 pmol of the control siGENOME nontargeting human siRNA pool 2 (all purchased from Dharmacon). Cells were harvested $48 \mathrm{~h}$ after transfection. siRNA sequences are as follows: siPTBP1, 5'-CUUCCAUCAUUCCAGAGAAUU-3'; si-PTBP2, 5'-GAGAGGAUCUGACGAACUAUU-3' (derived from Llorian et al. 2010). HCT116, DLD-1, LoVo, COLO320, and Caco-2 cells were treated with U0126 (Calbiochem) for RAS-MAPK pathway inhibition and were harvested after $24 \mathrm{~h}$; untreated cells were used as a control. Cell pellets from all experiments were divided to RNA and protein purification.

\section{Colon adenocarcinoma and normal colon samples}

Fresh-frozen (FF) tissue samples, both tumor and tumor-free (normal), from 19 colon adenocarcinoma patients (Supplemental Table S2) were obtained from the Institutional Tissue Banks at Sheba Medical Center following IRB approval and consent of patients.

\section{RNA purification, RT-PCR, quantitative RT-PCR, and KRAS sequencing}

RNA was extracted from cell lines with TRI reagent (Sigma). Total RNA was also isolated from human colon tumor samples and their matched normal tissue samples. Tissue samples were mechanically homogenized, and RNA was obtained using TRI reagent (Sigma), according to the manufacturer's protocol. After DNase I digestion

\section{Genome Research}

www.genome.org 
(Ambion), $2 \mu \mathrm{g}$ total RNA was reverse transcribed by SuperScript III (Invitrogen).

Splicing products were amplified with red load Taq master mix (Larova) or bio-ready mix (Biolab) and separated on 1.5\% agarose gel. In the cases of TPM1 and PKM alternative splicing events, PCR products were digested by PstI enzyme (New England BioLabs) prior to separation in $2 \%$ agarose gel. A qPCR analysis of mRNA expression in human tissue samples and cell lines was conducted using KAPA SYBR fast qPCR master mix (Kapa Biosystems) in a StepOne plus thermocycler PCR machine (Applied Biosystems) according to the manufacturer's instructions. Expression levels of HPRT1 and GAPDH genes were used as endogenous controls, and all of the samples were assayed in triplicate. Genes demonstrating an expression level increase of $>10 \%$ in each tumor sample in comparison with the matched normal sample were considered overexpressed for further statistical analyses. The log base 2 of all values were computed to meet the assumptions of the statistical tests. Variance similarity between examined groups was tested using an $F$-test, and in all cases, the variances were found to be different and treated as such in further statistical tests.

Known (Wood et al. 2007; The Cancer Genome Research Atlas Network 2012b) and novel colon cancer KRAS mutations were examined in tumor samples in comparison with their matched normal samples by Sanger sequencing following cDNA amplification.

\section{Data access}

Sanger sequencing data from this study have been submitted to the NCBI Trace Archive (http://www.ncbi.nlm.nih.gov/Traces/ home/) under TI numbers 2343078499-2343078575.

\section{Acknowledgments}

We thank Ran Elkon, Carmit Levy, Noam Shomron, and Rotem Karni for helpful discussions. We thank Nir Kfir for his help in preparing Figure 1B. G.A. was supported by grants from the Israel Science Foundation (ISF 61/09 and ISF 142/13). R.S. was supported by grants from the Israel Science Foundation (241/11 and I-CORE 757/12). D.H. and N.A. were partially supported by a fellowship of the Edmond J. Safra Bioinformatics Center at Tel Aviv University.

\section{References}

Adler AS, McCleland ML, Yee S, Yaylaoglu M, Hussain S, Cosino E, Quinones G, Modrusan Z, Seshagiri S, Torres E, et al. 2014. An integrative analysis of colon cancer identifies an essential function for PRPF6 in tumor growth. Genes Dev 28: 1068-1084.

Ahmed D, Eide PW, Eilertsen IA, Danielsen SA, Eknaes M, Hektoen M, Lind GE, Lothe RA. 2013. Epigenetic and genetic features of 24 colon cancer cell lines. Oncogenesis 2: e71.

Balasubramani M, Day BW, Schoen RE, Getzenberg RH. 2006. Altered expression and localization of creatine kinase $\mathrm{B}$, heterogeneous nuclear ribonucleoprotein $\mathrm{F}$, and high mobility group box 1 protein in the nuclear matrix associated with colon cancer. Cancer Res 66: 763-769.

Bechara EG, Sebestyen E, Bernardis I, Eyras E, Valcarcel J. 2013. RBM5, 6 , and 10 differentially regulate NUMB alternative splicing to control cancer cell proliferation. Mol Cell 52: 720-733.

Boutz PL, Stoilov P, Li Q, Lin CH, Chawla G, Ostrow K, Shiue L, Ares M Jr, Black DL. 2007. A post-transcriptional regulatory switch in polypyrimidine tract-binding proteins reprograms alternative splicing in developing neurons. Genes Dev 21: 1636-1652.

The Cancer Genome Research Atlas Network. 2008. Comprehensive genomic characterization defines human glioblastoma genes and core pathways. Nature 455: 1061-1068.

The Cancer Genome Research Atlas Network. 2011. Integrated genomic analyses of ovarian carcinoma. Nature 474: 609-615.
The Cancer Genome Research Atlas Network. 2012a. Comprehensive genomic characterization of squamous cell lung cancers. Nature 489 : $519-525$.

The Cancer Genome Research Atlas Network. 2012b. Comprehensive molecular characterization of human colon and rectal cancer. Nature 487: 330-337.

The Cancer Genome Research Atlas Network. 2012c. Comprehensive molecular portraits of human breast tumours. Nature 490: 61-70.

The Cancer Genome Research Atlas Network. 2013a. Comprehensive molecular characterization of clear cell renal cell carcinoma. Nature 499: 43-49.

The Cancer Genome Research Atlas Network. 2013b. Genomic and epigenomic landscapes of adult de novo acute myeloid leukemia. $N$ Engl J Med 368: 2059-2074.

Castle JC, Zhang C, Shah JK, Kulkarni AV, Kalsotra A, Cooper TA, Johnson JM. 2008. Expression of 24,426 human alternative splicing events and predicted cis regulation in 48 tissues and cell lines. Nat Genet 40: 1416-1425.

Chen M, Manley JL. 2009. Mechanisms of alternative splicing regulation: insights from molecular and genomics approaches. Nat Rev Mol Cell Biol 10: 741-754.

Chen M, Zhang J, Manley JL. 2010. Turning on a fuel switch of cancer: hnRNP proteins regulate alternative splicing of pyruvate kinase mRNA. Cancer Res 70: 8977-8980.

Choi JW, Kim DG, Lee AE, Kim HR, Lee JY, Kwon NH, Shin YK, Hwang SK, Chang SH, Cho MH, et al. 2011. Cancer-associated splicing variant of tumor suppressor AIMP2/p38: pathological implication in tumorigenesis. PLoS Genet 7: e1001351.

Choi C, Kim D, Kim S, Jeong S, Song E, Helfman DM. 2012. From skeletal muscle to cancer: insights learned elucidating the function of tropomyosin. J Struct Biol 177: 63-69.

Christofk HR, Vander Heiden MG, Harris MH, Ramanathan A, Gerszten RE, Wei R, Fleming MD, Schreiber SL, Cantley LC. 2008. The M2 splice isoform of pyruvate kinase is important for cancer metabolism and tumour growth. Nature 452: 230-233.

Clower CV, Chatterjee D, Wang Z, Cantley LC, Vander Heiden MG, Krainer AR. 2010. The alternative splicing repressors hnRNP A1/A2 and PTB influence pyruvate kinase isoform expression and cell metabolism. Proc Natl Acad Sci 107: 1894-1899.

Cohen-Eliav M, Golan-Gerstl R, Siegfried Z, Andersen CL, Thorsen K, Orntoft TF, Mu D, Karni R. 2013. The splicing factor SRSF6 is amplified and is an oncoprotein in lung and colon cancers. J Pathol 229: 630-639.

Cooper TA, Wan L, Dreyfuss G. 2009. RNA and disease. Cell 136: 777-793.

Cunningham D, Atkin W, Lenz HJ, Lynch HT, Minsky B, Nordlinger B, Starling N. 2010. Colorectal cancer. Lancet 375: 1030-1047.

Dang CV. 2012. MYC on the path to cancer. Cell 149: 22-35.

Das S, Anczuków O, Akerman M, Krainer AR. 2012. Oncogenic splicing factor SRSF1 is a critical transcriptional target of MYC. Cell Rep 1: 110-117.

David CJ, Manley JL. 2010. Alternative pre-mRNA splicing regulation in cancer: pathways and programs unhinged. Genes Dev 24: 2343-2364.

David CJ, Chen M, Assanah M, Canoll P, Manley JL. 2010. HnRNP proteins controlled by c-Myc deregulate pyruvate kinase mRNA splicing in cancer. Nature 463: 364-368.

Doudican NA, Mazumder A, Kapoor S, Sultana Z, Kumar A, Talawdekar A, Basu K, Agrawal A, Aggarwal A, Shetty K, et al. 2014. Predictive simulation approach for designing cancer therapeutic regimens with novel biological mechanisms. J Cancer 5: 406-416.

The ENCODE Project Consortium. 2012. An integrated encyclopedia of DNA elements in the human genome. Nature 489: 57-74.

Fearon ER. 2011. Molecular genetics of colorectal cancer. Annu Rev Pathol 6: 479-507.

Forbes SA, Bindal N, Bamford S, Cole C, Kok CY, Beare D, Jia M, Shepherd R, Leung K, Menzies A, et al. 2011. COSMIC: mining complete cancer genomes in the Catalogue of Somatic Mutations in Cancer. Nucleic Acids Res 39(Database issue): D945-D950.

Fournier G, Cabaud O, Josselin E, Chaix A, Adelaide J, Isnardon D, Restouin A, Castellano R, Dubreuil P, Chaffanet M, et al. 2011. Loss of AF6/afadin, a marker of poor outcome in breast cancer, induces cell migration, invasiveness and tumor growth. Oncogene 30: 3862-3874.

Gardina PJ, Clark TA, Shimada B, Staples MK, Yang Q, Veitch J, Schweitzer A, Awad T, Sugnet C, Dee S, et al. 2006. Alternative splicing and differential gene expression in colon cancer detected by a whole genome exon array. BMC Genomics 7: 325.

Ghigna C, Giordano S, Shen H, Benvenuto F, Castiglioni F, Comoglio PM, Green MR, Riva S, Biamonti G. 2005. Cell motility is controlled by SF2/ASF through alternative splicing of the Ron protooncogene. Mol Cell 20: 881-890.

Golan-Gerstl R, Cohen M, Shilo A, Suh SS, Bakacs A, Coppola L, Karni R. 2011. Splicing factor hnRNP A2/B1 regulates tumor suppressor gene splicing and is an oncogenic driver in glioblastoma. Cancer Res 71: 4464-4472. 
Goodarzi H, Elemento O, Tavazoie S. 2009. Revealing global regulatory perturbations across human cancers. Mol Cell 36: 900-911.

Graubert TA, Shen D, Ding L, Okeyo-Owuor T, Lunn CL, Shao J, Krysiak K, Harris CC, Koboldt DC, Larson DE, et al. 2011. Recurrent mutations in the $U 2 A F 1$ splicing factor in myelodysplastic syndromes. Nat Genet 44: 53-57.

Guigo R, Valcarcel J. 2006. Unweaving the meanings of messenger RNA sequences. Mol Cell 23: 150-151.

Hafner M, Landthaler M, Burger L, Khorshid M, Hausser J, Berninger P, Rothballer A, Ascano M Jr, Jungkamp AC, Munschauer M, et al. 2010. Transcriptome-wide identification of RNA-binding protein and microRNA target sites by PAR-CLIP. Cell 141: 129-141.

Hardt PD, Toepler M, Ngoumou B, Rupp J, Kloer HU. 2003. Measurement of fecal pyruvate kinase type M2 (tumor M2-PK) concentrations in patients with gastric cancer, colorectal cancer, colorectal adenomas and controls. Anticancer Res 23: 851-853.

He X, Arslan AD, Ho TT, Yuan C, Stampfer MR, Beck WT. 2014. Involvement of polypyrimidine tract-binding protein (PTBP1) in maintaining breast cancer cell growth and malignant properties. Oncogenesis 3: e84.

Hegele A, Kamburov A, Grossmann A, Sourlis C, Wowro S, Weimann M, Will CL, Pena V, Luhrmann R, Stelzl U. 2012. Dynamic protein-protein interaction wiring of the human spliceosome. Mol Cell 45: 567-580.

Heinz S, Benner C, Spann N, Bertolino E, Lin YC, Laslo P, Cheng JX, Murre C, Singh H, Glass CK. 2010. Simple combinations of lineage-determining transcription factors prime cis-regulatory elements required for macrophage and B cell identities. Mol Cell 38: 576-589.

Huelga SC, Vu AQ, Arnold JD, Liang TY, Liu PP, Yan BY, Donohue JP, Shiue L, Hoon S, Brenner S, et al. 2012. Integrative genome-wide analysis reveals cooperative regulation of alternative splicing by hnRNP proteins. Cell Rep 1: 167-178.

Ishimoto T, Nagano O, Yae T, Tamada M, Motohara T, Oshima H, Oshima M, Ikeda T, Asaba R, Yagi H, et al. 2011. CD44 variant regulates redox status in cancer cells by stabilizing the $\mathrm{xCT}$ subunit of system $\mathrm{xc}^{-}$and thereby promotes tumor growth. Cancer Cell 19: 387-400.

Jiang Y, Li X, Yang W, Hawke DH, Zheng Y, Xia Y, Aldape K, Wei C, Guo F, Chen Y, et al. 2014. PKM2 regulates chromosome segregation and mitosis progression of tumor cells. Mol Cell 53: 75-87.

Jin B, Yao B, Li JL, Fields CR, Delmas AL, Liu C, Robertson KD. 2009. DNMT1 and DNMT3B modulate distinct polycomb-mediated histone modifications in colon cancer. Cancer Res 69: 7412-7421.

Jordan P, Brazao R, Boavida MG, Gespach C, Chastre E. 1999. Cloning of a novel human Rac1b splice variant with increased expression in colorectal tumors. Oncogene 18: 6835-6839.

Kanehisa M, Goto S, Sato Y, Furumichi M, Tanabe M. 2012. KEGG for integration and interpretation of large-scale molecular data sets. Nucleic Acids Res 40(Database issue): D109-D114.

Karni R, de Stanchina E, Lowe SW, Sinha R, Mu D, Krainer AR. 2007. The gene encoding the splicing factor SF2/ASF is a proto-oncogene. Nat Struct Mol Biol 14: 185-193.

Keppetipola N, Sharma S, Li Q, Black DL. 2012. Neuronal regulation of premRNA splicing by polypyrimidine tract binding proteins, PTBP1 and PTBP2. Crit Rev Biochem Mol Biol 47: 360-378.

Kim E, Goren A, Ast G. 2008. Insights into the connection between cancer and alternative splicing. Trends Genet 24: 7-10.

Kishore S, Jaskiewicz L, Burger L, Hausser J, Khorshid M, Zavolan M. 2011. A quantitative analysis of CLIP methods for identifying binding sites of RNA-binding proteins. Nat Methods 8: 559-564.

Klinck R, Bramard A, Inkel L, Dufresne-Martin G, Gervais-Bird J, Madden R, Paquet ER, Koh C, Venables JP, Prinos P, et al. 2008. Multiple alternative splicing markers for ovarian cancer. Cancer Res 68: 657-663.

Kloetgen A, Munch PC, Borkhardt A, Hoell JI, McHardy AC. 2014 Biochemical and bioinformatic methods for elucidating the role of RNA-protein interactions in posttranscriptional regulation. Brief Funct Genomics 14: 102-114.

Konig J, Zarnack K, Rot G, Curk T, Kayikci M, Zupan B, Turner DJ, Luscombe NM, Ule J. 2010. iCLIP reveals the function of hnRNP particles in splicing at individual nucleotide resolution. Nat Struct Mol Biol 17: 909-915.

Langer W, Sohler F, Leder G, Beckmann G, Seidel H, Grone J, Hummel M, Sommer A. 2010. Exon array analysis using re-defined probe sets results in reliable identification of alternatively spliced genes in non-small cell lung cancer. BMC Genomics 11: 676.

Langmead B, Trapnell C, Pop M, Salzberg SL. 2009. Ultrafast and memoryefficient alignment of short DNA sequences to the human genome. Genome Biol 10: R25.

Lebedeva S, Jens M, Theil K, Schwanhausser B, Selbach M, Landthaler M, Rajewsky N. 2011. Transcriptome-wide analysis of regulatory interactions of the RNA-binding protein HuR. Mol Cell 43: 340-352.

Lee W, Jiang Z, Liu J, Haverty PM, Guan Y, Stinson J, Yue P, Zhang Y, Pant $\mathrm{KP}$, Bhatt D, et al. 2010. The mutation spectrum revealed by paired genome sequences from a lung cancer patient. Nature 465: 473-477.
Li Q, Zheng S, Han A, Lin CH, Stoilov P, Fu XD, Black DL. 2014. The splicing regulator PTBP2 controls a program of embryonic splicing required for neuronal maturation. eLife 3: e01201.

Lim SB, Yu CS, Jang SJ, Kim TW, Kim JH, Kim JC. 2010. Prognostic significance of lymphovascular invasion in sporadic colorectal cancer. Dis Colon Rectum 53: 377-384.

Liu J, Lee W, Jiang Z, Chen Z, Jhunjhunwala S, Haverty PM, Gnad F, Guan Y, Gilbert HN, Stinson J, et al. 2012. Genome and transcriptome sequencing of lung cancers reveal diverse mutational and splicing events. Genome Res 22: 2315-2327.

Llorian M, Schwartz S, Clark TA, Hollander D, Tan LY, Spellman R, Gordon A, Schweitzer AC, de la Grange P, Ast G, et al. 2010. Position-dependent alternative splicing activity revealed by global profiling of alternative splicing events regulated by PTB. Nat Struct Mol Biol 17: 1114-1123.

Mallinjoud P, Villemin JP, Mortada H, Polay Espinoza M, Desmet FO, Samaan S, Chautard E, Tranchevent LC, Auboeuf D. 2014 Endothelial, epithelial, and fibroblast cells exhibit specific splicing programs independently of their tissue of origin. Genome Res 24: 511-521.

Margalef P, Fernandez-Majada V, Villanueva A, Garcia-Carbonell R, Iglesias M, Lopez L, Martinez-Iniesta M, Villa-Freixa J, Mulero MC, Andreu M, et al. 2012. A truncated form of IKK $\alpha$ is responsible for specific nuclear IKK activity in colorectal cancer. Cell Rep 2: 840-854.

Mickleburgh I, Kafasla P, Cherny D, Llorian M, Curry S, Jackson RJ, Smith CW. 2014. The organization of RNA contacts by PTB for regulation of FAS splicing. Nucleic Acids Res 42: 8605-8620.

Misquitta-Ali CM, Cheng E, O'Hanlon D, Liu N, McGlade CJ, Tsao MS, Blencowe BJ. 2010. Global profiling and molecular characterization of alternative splicing events misregulated in lung cancer. Mol Cell Biol 31: $138-150$

Miura K, Fujibuchi W, Unno M. 2012. Splice isoforms as therapeutic targets for colorectal cancer. Carcinogenesis 33: 2311-2319.

Mukherjee N, Corcoran DL, Nusbaum JD, Reid DW, Georgiev S, Hafner M, Ascano M Jr, Tuschl T, Ohler U, Keene JD. 2011. Integrative regulatory mapping indicates that the RNA-binding protein HuR couples premRNA processing and mRNA stability. Mol Cell 43: 327-339.

Myant KB, Cammareri P, McGhee EJ, Ridgway RA, Huels DJ, Cordero JB, Schwitalla S, Kalna G, Ogg EL, Athineos D, et al. 2013. ROS production and NF- $\kappa \mathrm{B}$ activation triggered by RAC1 facilitate WNT-driven intestinal stem cell proliferation and colorectal cancer initiation. Cell Stem Cell 12. 761-773.

Pan Q, Shai O, Lee LJ, Frey BJ, Blencowe BJ. 2008. Deep surveying of alternative splicing complexity in the human transcriptome by high-throughput sequencing. Nat Genet 40: 1413-1415.

Papasaikas P, Tejedor JR, Vigevani L, Valcarcel J. 2015. Functional splicing network reveals extensive regulatory potential of the core spliceosomal machinery. Mol Cell 57: 7-22.

Pesson M, Volant A, Uguen A, Trillet K, De La Grange P, Aubry M, Daoulas M, Robaszkiewicz M, Le Gac G, Morel A, et al. 2014. A gene expression and pre-mRNA splicing signature that marks the adenoma-adenocarcinoma progression in colorectal cancer. PLoS One 9: e87761.

Pio R, Blanco D, Pajares MJ, Aibar E, Durany O, Ezponda T, Agorreta J, Gomez-Roman J, Anton MA, Rubio A, et al. 2010. Development of a novel splice array platform and its application in the identification of alternative splice variants in lung cancer. BMC Genomics 11: 352.

Quesada V, Conde L, Villamor N, Ordonez GR, Jares P, Bassaganyas L, Ramsay AJ, Bea S, Pinyol M, Martinez-Trillos A, et al. 2012. Exome sequencing identifies recurrent mutations of the splicing factor $S F 3 B 1$ gene in chronic lymphocytic leukemia. Nat Genet 44: 47-52.

Radisky DC, Levy DD, Littlepage LE, Liu H, Nelson CM, Fata JE, Leake D, Godden EL, Albertson DG, Nieto MA, et al. 2005. Rac1b and reactive oxygen species mediate MMP-3-induced EMT and genomic instability. Nature 436: 123-127.

Ramalingam S, Ramamoorthy P, Subramaniam D, Anant S. 2012. Reduced expression of RNA binding protein CELF2, a putative tumor suppressor gene in colon cancer. Immunogastroenterology 1: 27-33.

Rhead B, Karolchik D, Kuhn RM, Hinrichs AS, Zweig AS, Fujita PA, Diekhans M, Smith KE, Rosenbloom KR, Raney BJ, et al. 2010. The UCSC Genome Browser database: update 2010. Nucleic Acids Res 38(Database issue): D613-D619.

Roovers K, Wagner S, Storbeck CJ, O'Reilly P, Lo V, Northey JJ, Chmielecki J, Muller WJ, Siegel PM, Sabourin LA. 2009. The Ste20-like kinase SLK is required for ErbB2-driven breast cancer cell motility. Oncogene 28: 2839-2848

Saito R, Smoot ME, Ono K, Ruscheinski J, Wang PL, Lotia S, Pico AR, Bader GD, Ideker T. 2012. A travel guide to Cytoscape plugins. Nat Methods 9: 1069-1076.

Sanford JR, Wang X, Mort M, Vanduyn N, Cooper DN, Mooney SD, Edenberg HJ, Liu Y. 2009. Splicing factor SFRS1 recognizes a functionally diverse landscape of RNA transcripts. Genome Res 19: 381-394.

Schneider CA, Rasband WS, Eliceiri KW. 2012. NIH Image to ImageJ: 25 years of image analysis. Nat Methods 9: 671-675. 
Seo JS, Ju YS, Lee WC, Shin JY, Lee JK, Bleazard T, Lee J, Jung YJ, Kim JO, Shin JY, et al. 2012. The transcriptional landscape and mutational profile of lung adenocarcinoma. Genome Res 22: 2109-2119.

Shapiro IM, Cheng AW, Flytzanis NC, Balsamo M, Condeelis JS, Oktay MH Burge CB, Gertler FB. 2011. An EMT-driven alternative splicing program occurs in human breast cancer and modulates cellular phenotype. PLOS Genet 7: e1002218.

Singh A, Karnoub AE, Palmby TR, Lengyel E, Sondek J, Der CJ. 2004. Rac1b, a tumor associated, constitutively active Rac1 splice variant, promotes cellular transformation. Oncogene 23: 9369-9380.

Spellman R, Llorian M, Smith CW. 2007. Crossregulation and functional redundancy between the splicing regulator PTB and its paralogs $\mathrm{NPTB}$ and ROD1. Mol Cell 27: 420-434.

Srebrow A, Kornblihtt AR. 2006. The connection between splicing and cancer. J Cell Sci 119(Pt 13): 2635-2641.

Thorsen K, Sorensen KD, Brems-Eskildsen AS, Modin C, Gaustadnes M, Hein AM, Kruhoffer M, Laurberg S, Borre M, Wang K, et al. 2008 Alternative splicing in colon, bladder, and prostate cancer identified by exon array analysis. Mol Cell Proteomics 7: 1214-1224.

Tollervey JR, Curk T, Rogelj B, Briese M, Cereda M, Kayikci M, Konig J, Hortobagyi T, Nishimura AL, Zupunski V, et al. 2011. Characterizing the RNA targets and position-dependent splicing regulation by TDP43. Nat Neurosci 14: 452-458.

Venables JP, Klinck R, Koh C, Gervais-Bird J, Bramard A, Inkel L, Durand M, Couture S, Froehlich U, Lapointe E, et al. 2009. Cancer-associated regulation of alternative splicing. Nat Struct Mol Biol 16: 670-676.

Venables JP, Brosseau JP, Gadea G, Klinck R, Prinos P, Beaulieu JF, Lapointe E, Durand M, Thibault P, Tremblay K, et al. 2013. RBFOX2 is an important regulator of mesenchymal tissue-specific splicing in both normal and cancer tissues. Mol Cell Biol 33: 396-405.

Wang GS, Cooper TA. 2007. Splicing in disease: disruption of the splicing code and the decoding machinery. Nat Rev Genet 8: 749-761.

Wang C, Norton JT, Ghosh S, Kim J, Fushimi K, Wu JY, Stack MS, Huang S. 2008a. Polypyrimidine tract-binding protein (PTB) differentially affects malignancy in a cell line-dependent manner. J Biol Chem 283: 20277-20287.

Wang ET, Sandberg R, Luo S, Khrebtukova I, Zhang L, Mayr C, Kingsmore SF, Schroth GP, Burge CB. 2008b. Alternative isoform regulation in human tissue transcriptomes. Nature 456: 470-476.

Wang Z, Kayikci M, Briese M, Zarnack K, Luscombe NM, Rot G, Zupan B, Curk T, Ule J. 2010. iCLIP predicts the dual splicing effects of TIA-RNA interactions. PLoS Biol 8: e1000530.
Westhoff B, Colaluca IN, D'Ario G, Donzelli M, Tosoni D, Volorio S, Pelos G, Spaggiari L, Mazzarol G, Viale G, et al. 2009. Alterations of the Notch pathway in lung cancer. Proc Natl Acad Sci 106: 22293-22298.

Wood LD, Parsons DW, Jones S, Lin J, Sjoblom T, Leary RJ, Shen D, Boca SM, Barber T, Ptak J, et al. 2007. The genomic landscapes of human breast and colorectal cancers. Science 318: 1108-1113.

Xiao X, Wang Z, Jang M, Nutiu R, Wang ET, Burge CB. 2009. Splice site strength-dependent activity and genetic buffering by poly-G runs. Nat Struct Mol Biol 16: 1094-1100.

Xue Y, Zhou Y, Wu T, Zhu T, Ji X, Kwon YS, Zhang C, Yeo G, Black DL, Sun $\mathrm{H}$, et al. 2009. Genome-wide analysis of PTB-RNA interactions reveals a strategy used by the general splicing repressor to modulate exon inclusion or skipping. Mol Cell 36: 996-1006.

Xue Y, Ouyang K, Huang J, Zhou Y, Ouyang H, Li H, Wang G, Wu Q, Wei C, Bi Y, et al. 2013. Direct conversion of fibroblasts to neurons by reprogramming PTB-regulated microRNA circuits. Cell 152: 82-96.

Yang W, Xia Y, Ji H, Zheng Y, Liang J, Huang W, Gao X, Aldape K, Lu Z. 2011. Nuclear PKM2 regulates $\beta$-catenin transactivation upon EGFR activation. Nature 480: $118-122$.

Yeo GW, Coufal NG, Liang TY, Peng GE, Fu XD, Gage FH. 2009. An RNA code for the FOX2 splicing regulator revealed by mapping RNA-protein interactions in stem cells. Nat Struct Mol Biol 16: 130-137.

Yosef N, Ungar L, Zalckvar E, Kimchi A, Kupiec M, Ruppin E, Sharan R. 2009. Toward accurate reconstruction of functional protein networks. Mol Syst Biol 5: 248.

Yosef N, Zalckvar E, Rubinstein AD, Homilius M, Atias N, Vardi L, Berman I, Zur H, Kimchi A, Ruppin E, et al. 2011. ANAT: a tool for constructing and analyzing functional protein networks. Sci Signal 4: pl1.

Zhang J, Kong LM, Zhan R, Ye ZN, Pu JX, Sun HD, Li Y. 2014. Two natural ent-kauranoids as novel Wnt signaling inhibitors. Nat Prod Bioprospect 4: 135-140.

Zhou C, Licciulli S, Avila JL, Cho M, Troutman S, Jiang P, Kossenkov AV, Showe LC, Liu Q, Vachani A, et al. 2013. The Rac1 splice form Rac1b promotes K-ras-induced lung tumorigenesis. Oncogene 32: 903-909.

Zong FY, Fu X, Wei WJ, Luo YG, Heiner M, Cao LJ, Fang Z, Fang R, Lu D, Ji H, et al. 2014. The RNA-binding protein QKI suppresses cancer-associated aberrant splicing. PLoS Genet 10: e1004289.

Received April 15, 2015; accepted in revised form February 4, 2016. 


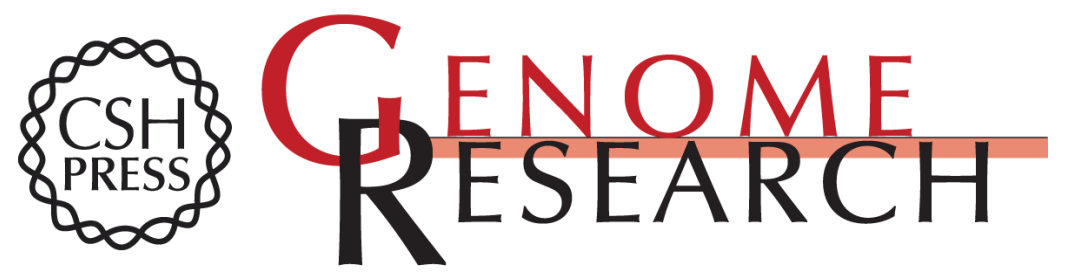

\section{A network-based analysis of colon cancer splicing changes reveals a tumorigenesis-favoring regulatory pathway emanating from ELK1}

Dror Hollander, Maya Donyo, Nir Atias, et al.

Genome Res. 2016 26: 541-553 originally published online February 9, 2016

Access the most recent version at doi:10.1101/gr.193169.115

\section{Supplemental} Material

References

Creative

Commons

License

Email Alerting Service
http://genome.cshlp.org/content/suppl/2016/02/11/gr.193169.115.DC1

This article cites 107 articles, 18 of which can be accessed free at: http://genome.cshlp.org/content/26/4/541.full.html\#ref-list-1

This article is distributed exclusively by Cold Spring Harbor Laboratory Press for the first six months after the full-issue publication date (see

http://genome.cshlp.org/site/misc/terms.xhtml). After six months, it is available under a Creative Commons License (Attribution-NonCommercial 4.0 International), as described at http://creativecommons.org/licenses/by-nc/4.0/.

Receive free email alerts when new articles cite this article - sign up in the box at the top right corner of the article or click here.

\section{Affordable, Accurate Sequencing.}

